\title{
Effect of Auxiliary Blade on Aerodynamic Characteristics of Vertical Axis Wind Turbine by Numerical Simulation
}

\author{
Yan Li $\mathbb{D}^{1},{ }^{1,2}$ Chang Zhao, ${ }^{1}$ Chunming Qu, ${ }^{1}$ Shouyang Zhao, \\ Fang Feng $\oplus^{,}{ }^{3}$ and Kotaro Tagawa ${ }^{4}$ \\ ${ }^{1}$ Engineering College, Northeast Agricultural University Harbin, Heilongjiang 150030, China \\ ${ }^{2}$ Heilongjiang Provincial Key Laboratory of Technology and Equipment for the Utilization of Agricultural Renewable Resources in \\ Cold Region, Harbin, Heilongjiang 150030, China \\ ${ }^{3}$ College of Science, Northeast Agricultural University, Harbin, 150030, China \\ ${ }^{4}$ Faculty of Agriculture, Tottori University, Tottori, 6808551, Japan
}

Correspondence should be addressed to Yan Li; liyanneau@163.com

Received 1 August 2018; Revised 17 January 2019; Accepted 18 March 2019; Published 21 April 2019

Academic Editor: Funazaki Ken-ichi

Copyright (C) 2019 Yan Li et al. This is an open access article distributed under the Creative Commons Attribution License, which permits unrestricted use, distribution, and reproduction in any medium, provided the original work is properly cited.

In order to improve the aerodynamic characteristics of the Straight-bladed Vertical Axis Wind Turbine (SB-VAWT), a rotor structure with auxiliary blade installed behind the main blade was proposed in this study. To investigate the effects of relative thickness and the fixing angle of the auxiliary blade on aerodynamic characteristics of SB-VAWT, numerical simulations were carried out. Two shapes of NACA 4-digital series blade-section, NACA0018 and NACA0024, were selected as the main blades in this work. Effects of relative thickness and fixing angles of auxiliary blade on the aerodynamic performance of SB-VAWT had been analyzed in detail, which had 5 kinds of relative thickness and 3 kinds of fixing angles combined into 13 working conditions. And the main blades and the auxiliary blades were also decided as the NACA series airfoil with five kinds of relative thickness. Three kinds of fixing angle of auxiliary blade installed behind main blade were used including $0^{\circ}, 5^{\circ}$, and $10^{\circ}$. The simulations included the output power coefficients, the static torque coefficients, and the flow fields around the main blade and auxiliary blade for both the dynamic and static conditions at some typical azimuth angles. The results show that the auxiliary blade with certain relative thickness and fixing angle can improve the output power characteristics and static torque characteristics of SB-VAWT, which can also provide research reference for improving the performance of VAWT.

\section{Introduction}

In recent years, with the global environmental deterioration and energy shortage becoming increasingly prominent, the research and utilization of clean and renewable energy sources have been paid more and more attention in the world. Among them, wind energy has become one of the most widely used renewable energy sources [1-3]. Under the background of rapid development of large-scale wind power, the small- and medium-scale wind power industry is also developing and expanding generally [4]. Although the Horizontal Axis Wind Turbine (HAWT) is still the popular type in this field, another important type of wind turbines, the Straight-bladed Vertical Axis Wind Turbine (SBVAWT), has received more and more attention by researchers recently [5]. Some research reports indicated that the SBVAWT can be used in the offshore wind turbines $[6,7]$. However, compared with the HAWT, there are some shortcomings of SB-VAWT such as relative low power coefficient, starting performance problem under low wind speed [8]. To improve the aerodynamic characteristics of SB-VAWT, some methods were proposed by researches including adding some drag type wind turbine into the rotor, installing wind gathering device around the rotor, and inventing new blade airfoil and improving the flow field around blade at larger attack angles [9-11]. In this study, improving the flow fields around blades has been focused on to increase the aerodynamic performance. Based on the past researches, it is known that flow fields around blades and rotor are rather complex with large vortex and separation during blade rotation process 
[12-14]. Some researchers made efforts to develop new blade airfoils suitable for SB-VAWT, such as Prof. Seki who invented the TWT airfoil [15]. Other researchers made some changes on original blade to decrease vortex and separation, for example, by adding winglet $[16,17]$, making gap or slotting on blade surface [18], and adding auxiliary flat or blade at trailing edge $[19,20]$. Yan $\mathrm{Li}$ [21] proposed a method by adding auxiliary blades behind the main blade of SB-VAWT to improve the flow field around main blade and the wake of rotor. The chord length ratio and installation position between the main and auxiliary blades had been studied. The results showed that the chord length ratio was 0.4 and the installation position of auxiliary blade was $14^{\circ}$ behind the main blade, improving the performance of VAWTs. Liao Xueshu [22] analyzed the effect of relative thickness of blade on VAWT efficiency. The results showed that the relative thickness was an important geometric parameter for airfoils selection. Yang Qiuping [23] proposed that the fixing angle of blades had a certain influence on the output power of VAWT. Initial results show that this method is effective in improving the aerodynamic performance of SB-VAWT [22].

Based on [21], the method of adding auxiliary blades after main blades was also used in this study. The previous research had only proposed the method and initially verified the feasibility of this method. However, this research conducted in-depth parameter optimization compared with the previous research. In this study, the relative thickness and fixing angle of auxiliary blades were taken as the main research parameters to be optimized. The research builds a foundation for the further study of flow mechanism on this topic. And the method of changing the relative thickness and fixing angle provides a new idea for the future research of VAWTs. And this provides a reference for the whole parameter optimization system. The effects of two parameters on aerodynamic characteristics of VAWTs will be studied further by numerical simulations. Five kinds of thickness and three kinds of fixing angle are selected for research comparing with the original type two-bladed SB-VAWT. The simulations include the output power coefficients, the static torque coefficients, and the flow fields around the main blade and auxiliary blade for both the dynamic and static conditions at some typical azimuth angles.

\section{Model Design}

NACA series blade-section is currently the most commonly used and has also proven to be one of the most effective airfoils [24]. In this study, NACA 4-digital series airfoils were selected for both main and auxiliary blades. Figure 1 shows the concept of auxiliary blade installed behind the main blade of two-bladed SB-VAWT. The main blade shown in Figure 1(a) is named Blade I, and another main blade on the other side against Blade I which is not shown in the figure is named Blade II. Behind the main Blade I an auxiliary blade was added to improve the flow field around the main blade. The angle between the blade chord and the wind rotor tangent is the fixing angle. The attack angle is changed by the changes of the fixing angle.

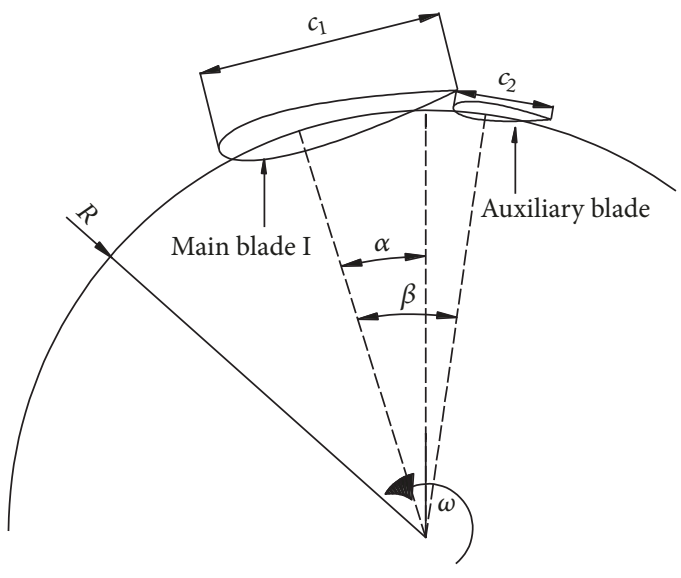

(a) Main blade with auxiliary blade

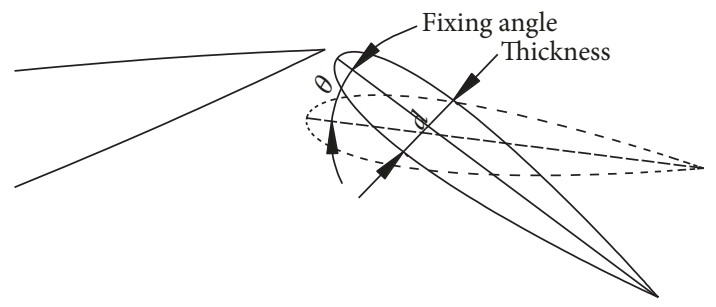

(b) Parameters of auxiliary blade

FIgURE 1: SB-VAWT with auxiliary blade.

Figure 1(b) shows the two parameters including thickness and fixing angle of the auxiliary blade. The position of the dashed blade is defined as the fixing angle $0^{\circ}$. The position of the solid blade is defined as the fixing angle $-\theta^{\circ}$. The thickness of the blade is the distance between the upper and lower inner surface perpendicular to the blade chord. The relative thickness is defined as (1) which is shown as follows. The four numbers of the NACA4-digital series represent different meanings. The last two digits indicate the relative thickness, such as the relative thickness of NACA0018 is $18 \%$ :

$$
\varepsilon=\frac{d}{C}
$$

where $\varepsilon$ is the relative thickness of blade, $d(\mathrm{~mm})$ is thickness of the blade, and $C(\mathrm{~mm})$ is chord length of the blade.

Other main parameters were studied before, such as distance between main blade and auxiliary blade and blade airfoil [13]. For both the main blade and the auxiliary blade, the NACA symmetric series airfoils were used. Therefore, the thickness of auxiliary blade can be easily changed under the same chord length. The parameter values of rotor model designed were based on the past researches and considered for carrying out wind tunnel tests in the future for comparison. Table 1 shows the parameters of the main blade and auxiliary blade of rotor model. Table 2 shows two working conditions named A and B for numerical simulation. Two kinds of thickness of main blade were selected. Five kinds of thickness and three kinds of fixing angle of auxiliary blade were used. The wind speed is $10 \mathrm{~m} / \mathrm{s}$. 
TABLE 1: Parameters of rotor model.

\begin{tabular}{lc}
\hline Parameters & Information \\
\hline Number of main blades & 2 \\
Number of auxiliary blades & 2 \\
Chord length of main blade/m & 0.125 \\
Chord length of auxiliary blade/m & 0.05 \\
Wind rotor radius $\mathrm{R} / \mathrm{m}$ & 0.4 \\
Main blade airfoil & NACA0018, NACA0024 \\
\hline & NACA0012, NACA0018 \\
Auxiliary blade airfoil & NACA0022, NACA0024 \\
& NACA0026 \\
\hline Relative angle between main blade and auxiliary blade $\beta$ & $14^{\circ}$
\end{tabular}

TABLE 2: Working conditions for simulation.

\begin{tabular}{|c|c|c|c|c|}
\hline Working conditions & & Main blade airfoil & Auxiliary blade airfoil & Fixing angle $\theta\left(^{\circ}\right)$ \\
\hline \multirow{7}{*}{$\begin{array}{l}\text { Working condition A } \\
\text { (WCA) }\end{array}$} & $\mathrm{A}_{0}$ & NACA0018 & 1 & 1 \\
\hline & $\mathrm{A}_{1}$ & NACA0018 & NACA0012 & $0^{\circ}$ \\
\hline & $\mathrm{A}_{2}$ & NACA0018 & NACA0012 & $5^{\circ}$ \\
\hline & $\mathrm{A}_{3}$ & NACA0018 & NACA0012 & $10^{\circ}$ \\
\hline & $\mathrm{A}_{4}$ & NACA0018 & NACA0018 & $0^{\circ}$ \\
\hline & $\mathrm{A}_{5}$ & NACA0018 & NACA0018 & $5^{\circ}$ \\
\hline & $\mathrm{A}_{6}$ & NACA0018 & NACA0018 & $10^{\circ}$ \\
\hline \multirow{6}{*}{$\begin{array}{l}\text { Working Condition B } \\
\text { (WCB) }\end{array}$} & $\mathrm{B}_{0}$ & NACA0024 & 1 & 1 \\
\hline & $\mathrm{B}_{1}$ & NACA0024 & NACA0012 & $0^{\circ}$ \\
\hline & $\mathrm{B}_{2}$ & NACA0024 & NACA0018 & $0^{\circ}$ \\
\hline & $\mathrm{B}_{3}$ & NACA0024 & NACA0022 & $0^{\circ}$ \\
\hline & $\mathrm{B}_{4}$ & NACA0024 & NACA0024 & $0^{\circ}$ \\
\hline & $\mathrm{B}_{5}$ & NACA0024 & NACA0026 & $0^{\circ}$ \\
\hline
\end{tabular}

\section{Method}

3.1. Numerical Simulation. Figure 2 shows the main geometrical features of the computational domain. The SB-VAWT operated in open field conditions, so it is necessary to be a large domain to avoid blockage. To make the calculation more simplify, some components such as the beams and axis were not considered in simulation. The calculation domain was a rectangular area with eight times the width and fifteen times the length of the diameter of SB-VAWT. Two-dimensional model numerical simulation method was adopted in this study, which can simplify the calculation of the structure because the vortex of the blade at the trailing edge of the blade and its influence were not considered [25]. A finite volume CFD solver ANSYS FLUENT was used with the implementation of Reynolds averaged Navier-Stokes equations. The RNG $\mathrm{k}-\varepsilon$ model was known to more accurately predict flow field involving large flow separation [26]. Therefore, the numerical simulation of SB-VAWT flow field used the RNG k- $\varepsilon$ model to calculate the turbulence. The rotation effect was considered, so the precision was higher when the strong rotation flow was calculated in this model $[27,28]$. The pressure velocity coupling was the SIMPLEC algorithm, and the flow was unsteady. The convective item was second order upwind scheme. In the numerical simulation, the calculation error of each equation was set to $10^{-6}$. The transport equations for the RNG $\mathrm{k}-\varepsilon$ turbulence model and turbulent viscosity are presented as (2) and (3). The equations for turbulence intensity and Reynolds number are shown as (4) and (5). According to the calculation, the inlet turbulence intensity in this paper is 0.030676454 , and the relaxation factor was selected as default value of 0.7 :

$$
\begin{aligned}
\frac{\partial(\rho \mathrm{k})}{\partial \mathrm{t}}+\frac{\partial\left(\rho k u_{i}\right)}{\partial x_{i}}= & \frac{\partial}{\partial x_{j}}\left(\alpha_{k} \mu_{e f f} \frac{\partial k}{\partial x_{j}}\right)+G_{k}+G_{b} \\
& -\rho \varepsilon-Y_{M} \\
\frac{\partial(\rho \mathrm{k})}{\partial \mathrm{t}}+\frac{\partial\left(\rho k u_{i}\right)}{\partial x_{i}}= & \frac{\partial}{\partial x_{j}}\left(\alpha_{\varepsilon} \mu_{e f f} \frac{\partial k}{\partial x_{j}}\right) \\
& +G_{1 \varepsilon} \frac{\varepsilon}{\mathrm{k}}\left(G k+C_{3 \varepsilon} G_{b}\right) \\
& -C_{2 \varepsilon} \rho \frac{\varepsilon^{2}}{k}-R_{\varepsilon} \\
I= & 0.16 \operatorname{Re} e^{-1 / 8} \\
\operatorname{Re}= & \frac{2 U R \rho}{\mu}
\end{aligned}
$$




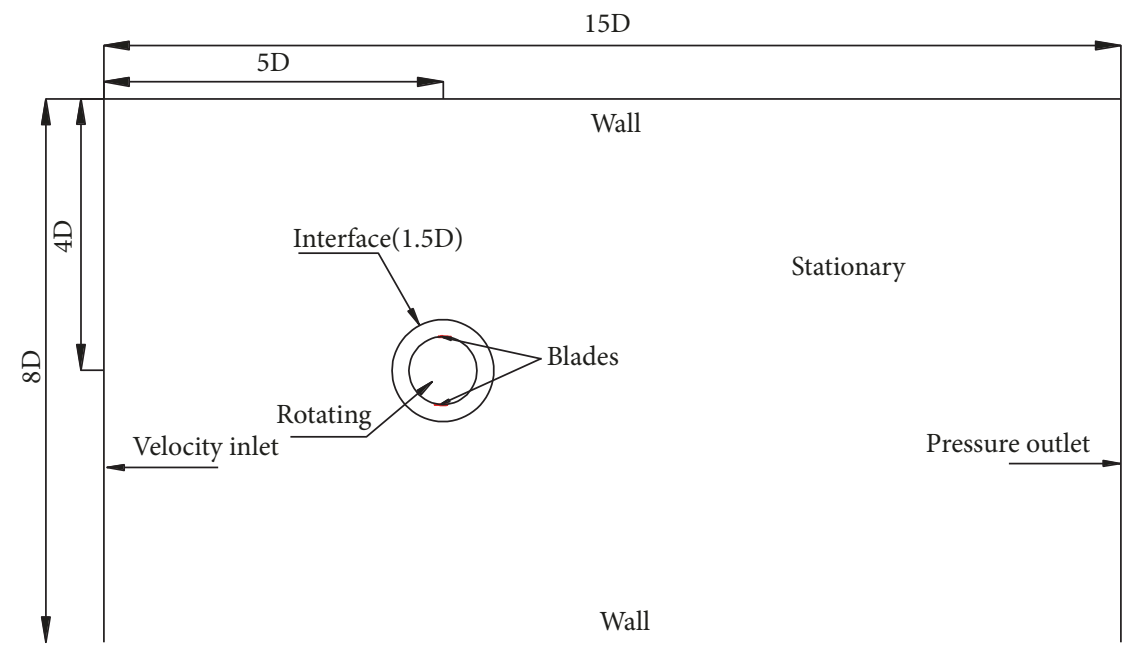

FIgURE 2: Computational domain and boundary conditions.

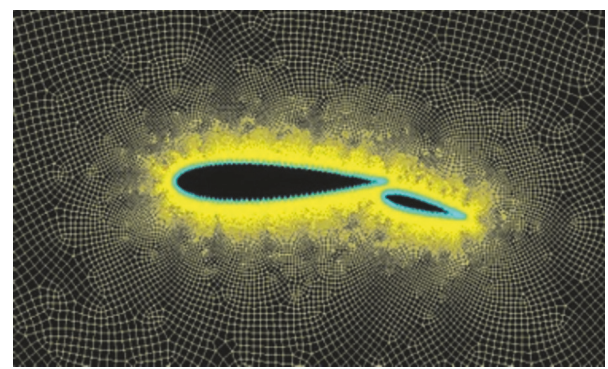

FIgure 3: Mesh around blades.

where $G_{\mathrm{k}}$ is the turbulent kinetic energy term due to the mean velocity gradient; $G_{\mathrm{b}}$ is the turbulent kinetic energy $k$ due to buoyancy; $Y_{\mathrm{M}}$ is the contribution of pulsating expansion in compressible turbulence; $C_{1 \varepsilon}=1.42, C_{2 \varepsilon}=1.68, C_{3 \varepsilon}=0.0845$ are empirical constants; $\alpha_{\mathrm{k}}$ and $\alpha_{\varepsilon}$ are the Prandtl numbers, respectively, corresponding to the turbulence kinetic $\mathrm{k}$ and dissipation $\varepsilon$; $I$ is turbulence intensity; Re is the Reynolds number; $U(\mathrm{~m} / \mathrm{s})$ is the inlet wind speed; $R(\mathrm{~m})$ is rotor radius; $\rho(\mathrm{kg} / \mathrm{m} 3)$ is air density; and $\mu(\mathrm{kg} / \mathrm{m} \bullet \mathrm{s})$ is coefficient of kinetic viscosity.

The grid contribution of working condition A4 is shown in Figure 3. The unstructured mesh was used in the computational domain. And the mesh surface of the blade was encrypted. Figure 4 shows grid-independence verification taking $\mathrm{A}_{4}$ as an example. When the number of grid nodes is greater than 2211997, the static torque coefficient is basically stable. After considering comprehensively the calculation time and accuracy, this study selected about 250000 grids as the calculation conditions, which meant that the start size of grid was 0.1, the growth factor was 1.05, and the maximum size was 5 for the rotation zone; the start size of grid in static zone was 5 , the growth factor was 1.05 , and the maximum size was 50 . Through refining the near-wall grids, the value of $y+$ was set as about 30 .

3.2. Comparison of Simulation and Experiment. To verify the reliability of numerical simulation, a comparison between

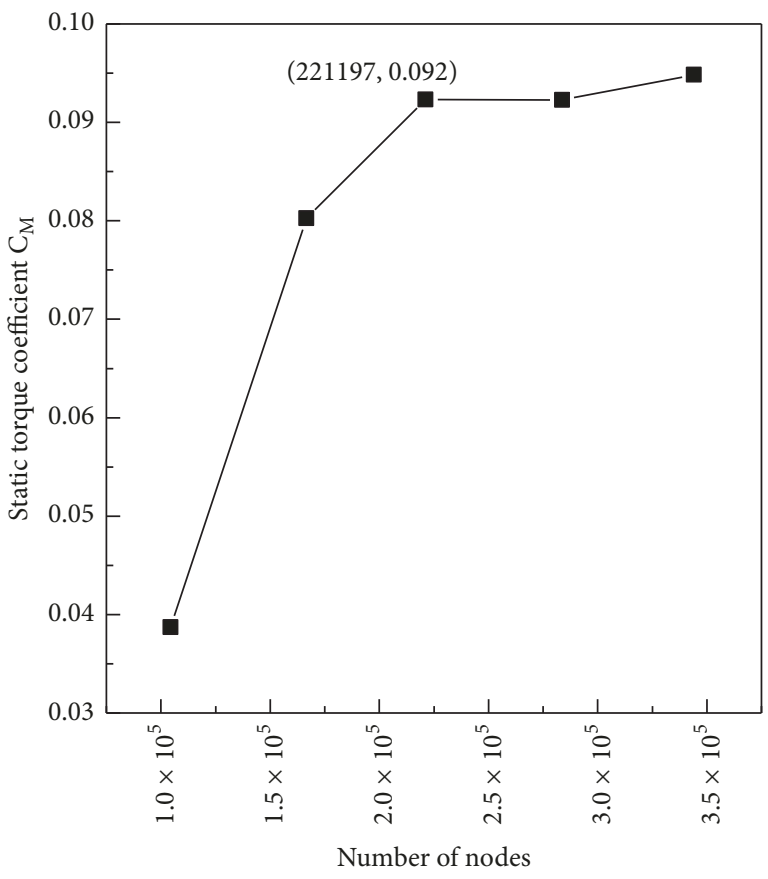

FIGURE 4: Mesh independent verification.

numerical simulation and wind tunnel test was carried out. Figure 5 shows the power coefficients $\left(C_{\mathrm{p}}\right)$ as a function of tip speed ratio $(\lambda)$ obtained by the simulation and experiment results based on past researches [19]. The power coefficient and tip speed ratio are defined as (6) and (7) as shown below:

$$
\begin{aligned}
C_{\mathrm{p}} & =\frac{P}{(1 / 2) \rho A R U^{3}} \\
\lambda & =\frac{\omega R}{U}
\end{aligned}
$$

where $\omega(\mathrm{rad} / \mathrm{s})$ is angular velocity of the rotor, $\mathrm{R}(\mathrm{m})$ is rotor radius, $U(\mathrm{~m} / \mathrm{s})$ is the incoming flow velocity, $\rho(\mathrm{kg} / \mathrm{m} 3)$ is air density, and A (m2) is the cross-sectional area of the rotor. 


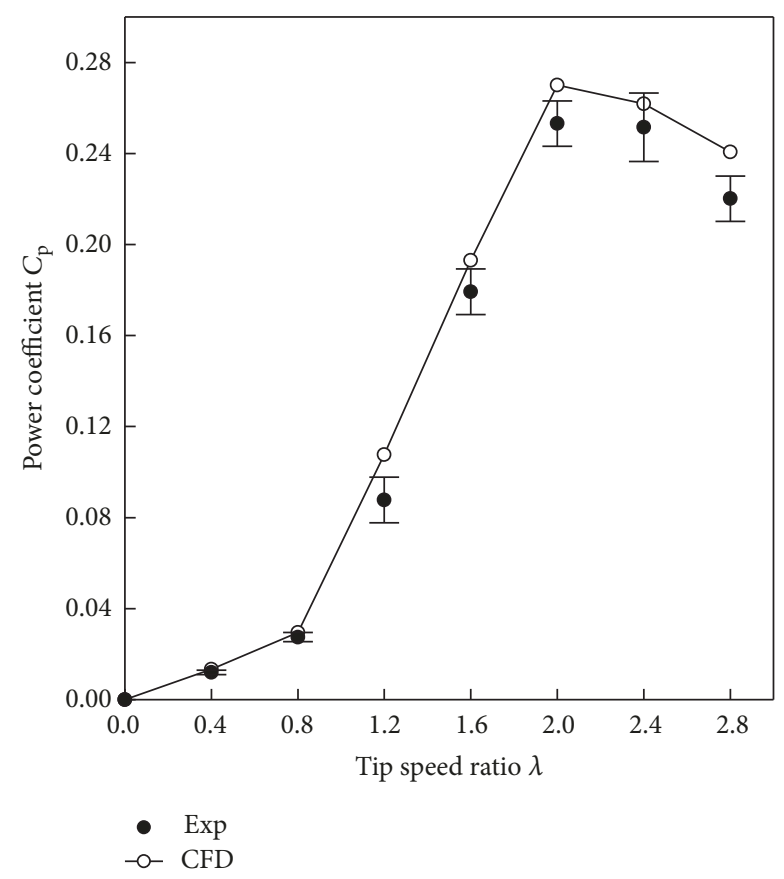

FIGURE 5: Power coefficients of wind turbine by simulation and experiment.

These numerical simulation results have similar trends to the experimental results, although a slight discrepancy exists; the results of the numerical simulations are higher than the experiments. The main reason can be that the simplified model ignores the losses of friction, beam, and axis in the experimental system. The relative error between the experiment results and simulation results is about $4.5 \%$ at the tip speed ratio of 2.4. Therefore, the method could be used to research in this study.

\section{Results and Discussion}

4.1. Power Characteristics. Figure 6 shows the power coefficient at different tip speed ratios under all working conditions. The output power of SB-VAWT equipped with auxiliary blades is improved generally for WCA. The overall power coefficient in WCA is better than WCB. It can be seen that the output power of $A_{5}$ is obviously superior to the other working conditions such that it increased by about $12.2 \%$ more than the rotor with no auxiliary blade at the tip speed ratio of 2.0. Therefore, the flow field analyses in WCA were based on the working condition of $\mathrm{A}_{0}$ and $\mathrm{A}_{5}$.

For WCB, the maximum power coefficients of the rotor with auxiliary blade become lower than the rotor without auxiliary blade. However, the power coefficients become obviously better when the tip speed ratio is from 0.6 to 1.6. This indicates that the auxiliary is effective in improving the power performance at low tip speed ratio when the rotor has thinner relative thickness. The flow field analyses in WCB were based on the working condition of $\mathrm{B}_{0}$ and $\mathrm{B}_{3}$.

4.2. Torque Coefficient in One Rotation Period. Figure 7 shows the torque coefficients $\left(C_{\mathrm{T}}\right)$ at different azimuth angles in a rotation period. The torque coefficient is defined as (8) as shown below:

$$
C_{T}=\frac{T}{(1 / 2) \rho A R U^{2}}
$$

where $T(\mathrm{~N} \cdot \mathrm{m})$ is the torque absorbed by a wind turbine.

A rotation period of a two-bladed wind rotor is $180^{\circ}$. The torque coefficients under the working conditions of $A_{0}, A_{5}$, $B_{0}$, and $B_{3}$ were simulated. The tip speed ratio for $A_{0}$ and $A_{5}$ is 2.0 and 1.0 for $\mathrm{B}_{0}$ and $\mathrm{B}_{3}$, respectively. The azimuth angle interval is $10^{\circ}$.

For the wording conditions of $\mathrm{A}_{0}$ and $\mathrm{A}_{5}$, the change trend of power coefficient is almost the same. From $0^{\circ}$ to $80^{\circ}$, there is no larger difference in power coefficient for both the two types of rotor. However, the power coefficients of the rotor with auxiliary blade become higher than that without auxiliary blade. When the azimuth angle is around $110^{\circ}$, the maximum output power is achieved in $\mathrm{A}_{0}$ and $\mathrm{A}_{5}$, and the power coefficient of $\mathrm{A}_{5}$ is about $11.42 \%$ higher than that of $\mathrm{A}_{0}$. This indicates that the auxiliary blade plays an important role in increasing power performance of SB-VAWT only at some certain azimuth angles, not for the whole rotation period. On the other hand for the working condition of $B_{0}$ and $B_{3}$, the results are quite different. First, there are no negative values for the rotor with auxiliary blade, which indicates that the existence of auxiliary blade greatly improves the power performance of SB-VAWT. Furthermore, the power coefficients of the rotor with auxiliary blade are higher than that of the original rotor; besides that the azimuth angles are between $40^{\circ}$ and $80^{\circ}$. The maximum power coefficient occurs at the azimuth angle of $90^{\circ}$. The power coefficient in the working condition $\mathrm{B}_{3}$ is about $18.89 \%$ higher than that of $\mathrm{B}_{0}$.

4.3. Dynamic Flow Field. Figure 8 shows the distribution of velocity and pressure around the blades under the working conditions of $\mathrm{A}_{0}$ and $\mathrm{A}_{5}$ at three typical azimuth angles of $0^{\circ}$, $20^{\circ}$, and $110^{\circ}$ based on the analysis above. Figure 9 shows the velocity contours of working condition A.

For $\alpha=0^{\circ}$, according to Figure 8(a), the pressure distributions on the upper and lower side of Blade I change greatly for the existence of auxiliary blade. The back flow from the trailing edgy to upper side towards the leading edge was also decreased. There is no obvious difference in flow field between the two types of rotor for Blade II.

Therefore, the flow field characteristics improve power performance. For $\alpha=20^{\circ}$, according to Figure 8(b), like the condition of $\alpha=0^{\circ}$, the pressure on the lower side of Blade I was changed a little only. Furthermore, the auxiliary blade also changed the flow field and pressure distribution at the trailing edge of Blade I. There is also no obvious difference in flow field between the two types of rotor for Blade II. Therefore, the power coefficients of the two types of rotor are also the same. For $\alpha=110^{\circ}$, according to Figure 8(c), it can be found that there are obvious differences in flow field and pressure between the two types of rotor around Blade I. By the existence of auxiliary, the difference of pressure between the upper side and lower side becomes rather bigger than the rotor without auxiliary. The whole swept area with 


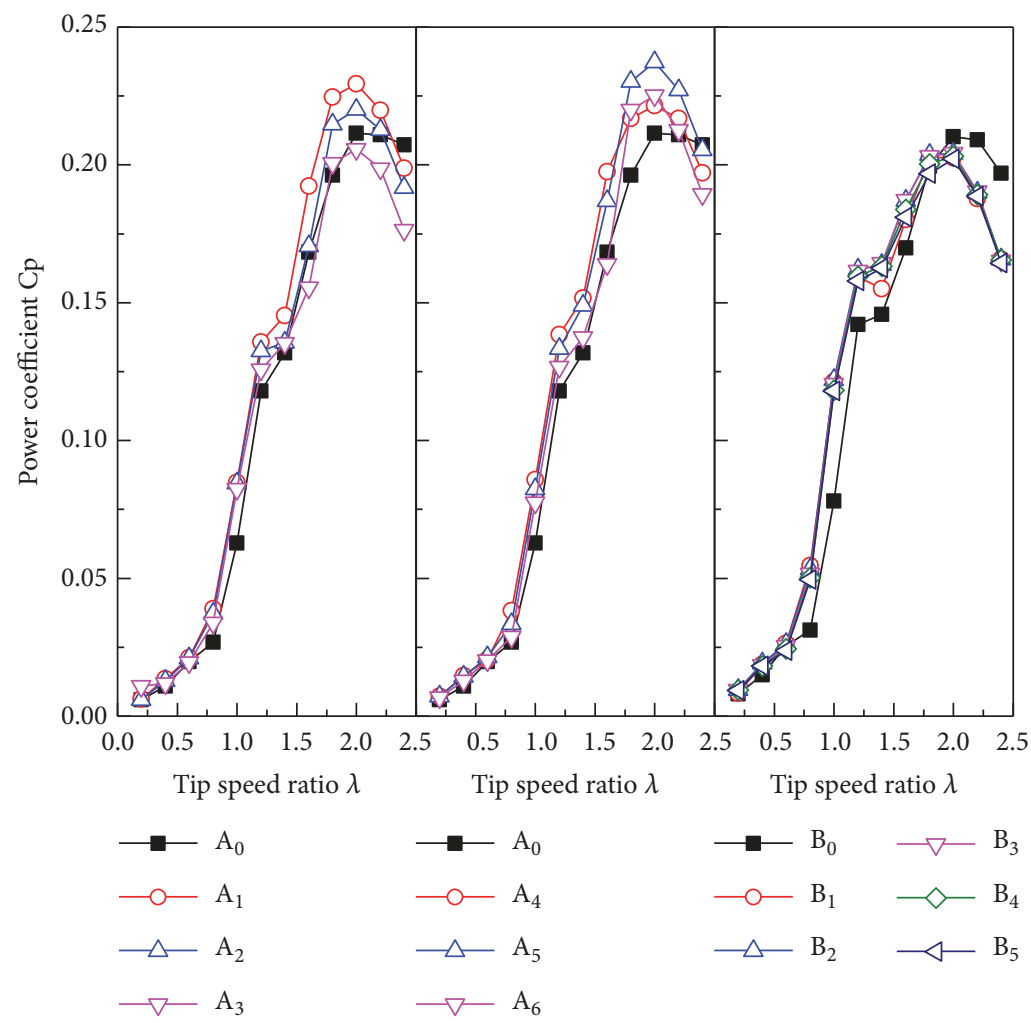

FIgURE 6: Power coefficients for different working conditions.

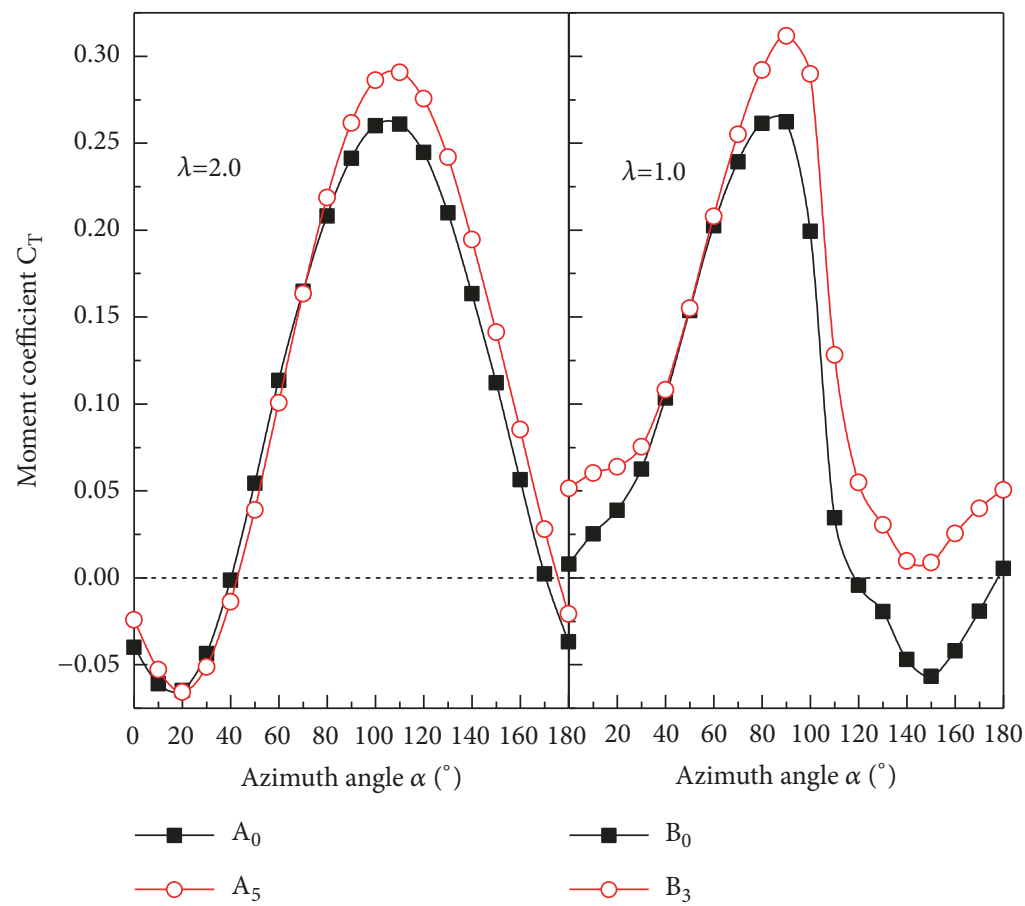

FIgURE 7: Torque coefficients in one rotation period. 


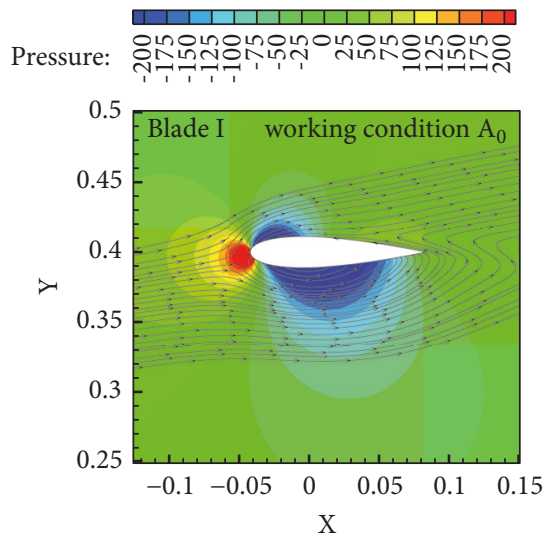

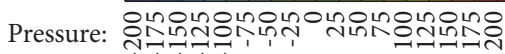

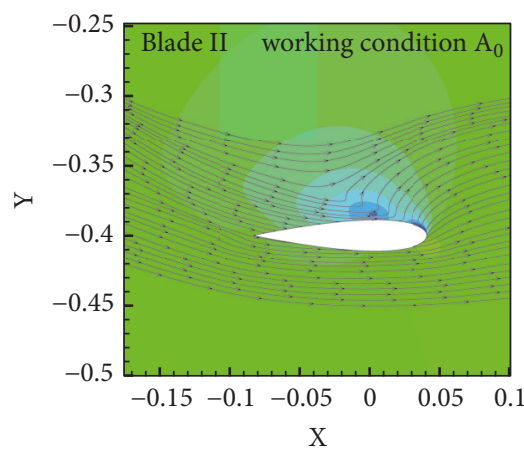

Pressure:
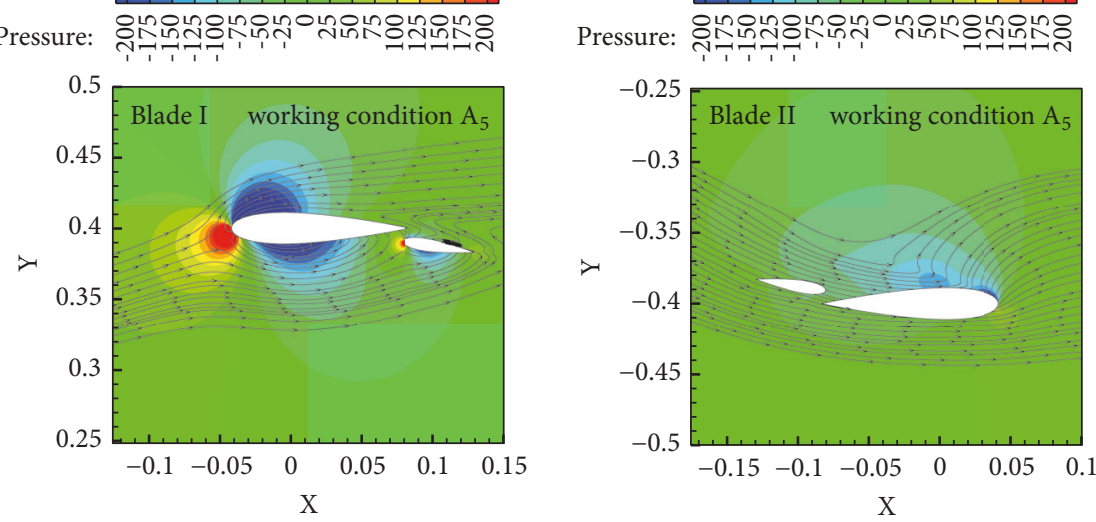

(a) $\alpha=0^{\circ}$

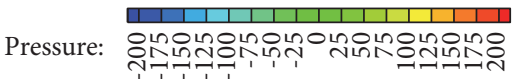

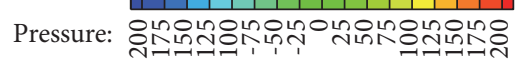
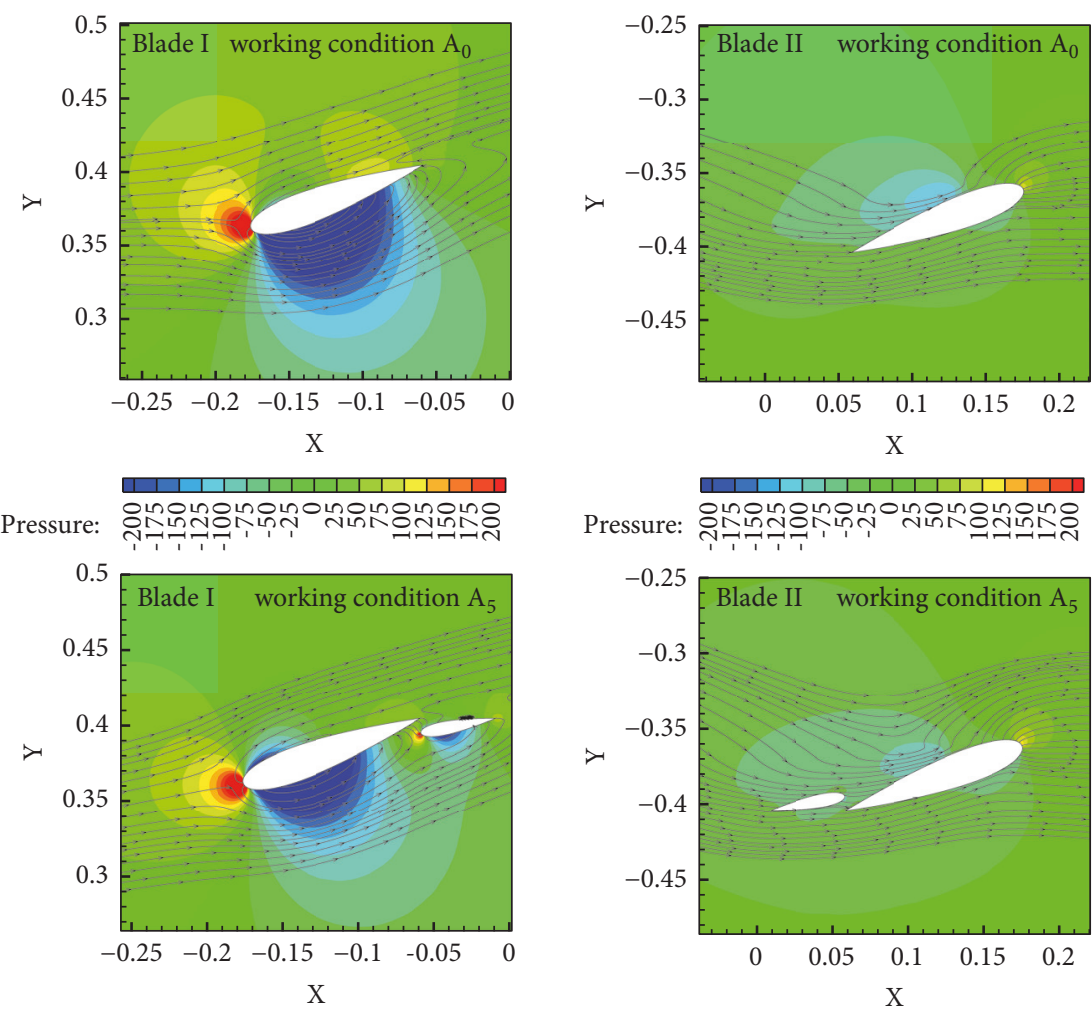

(b) $\alpha=20^{\circ}$

FIgure 8: Continued. 

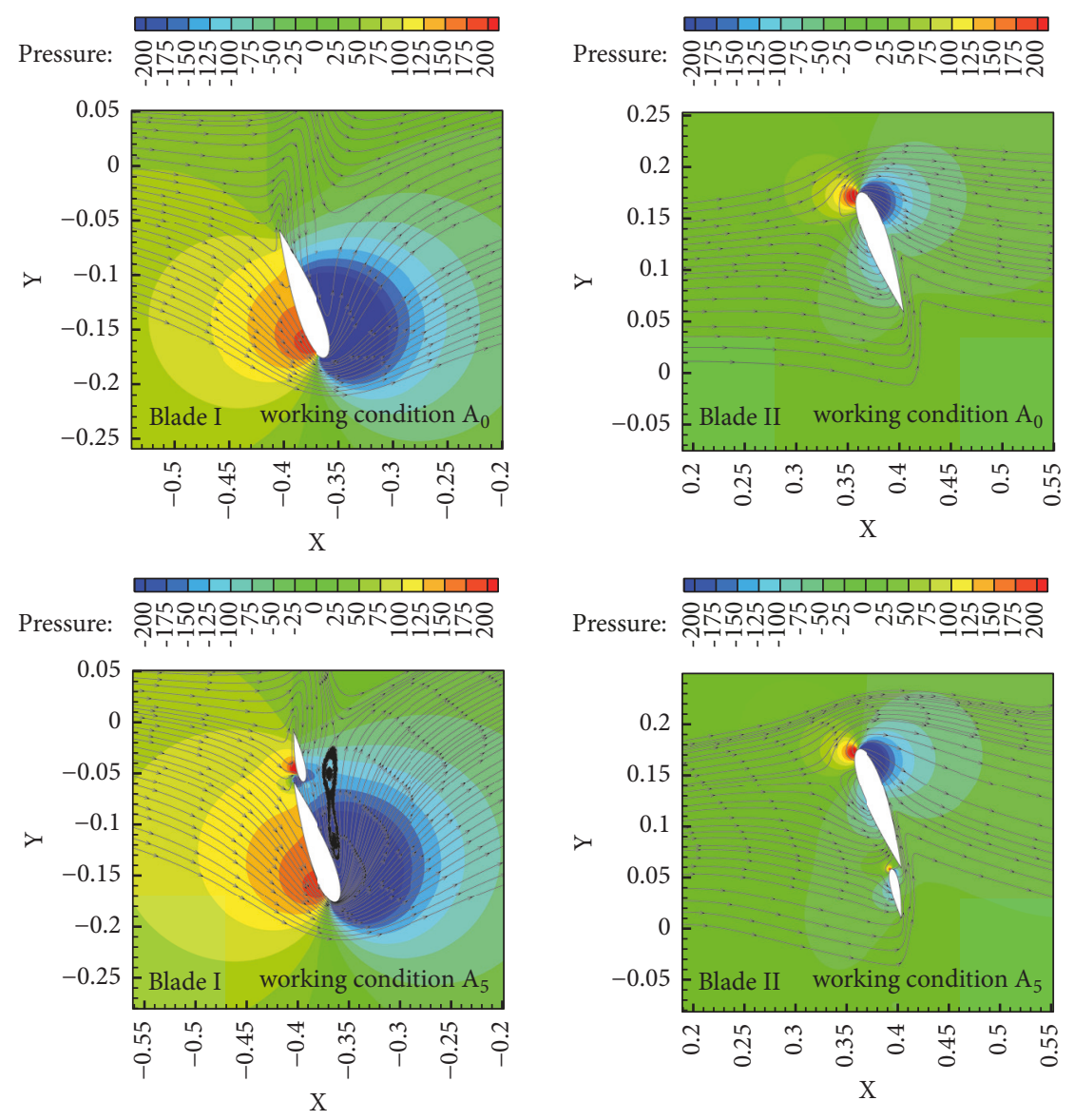

(c) $\alpha=110^{\circ}$

FIGURE 8: Streamline and pressure contours around wind turbine blade of working condition A.

the auxiliary blade becomes larger than the original rotor. Therefore, the rotor with auxiliary blade can produce more torque and power. For the condition of Blade II, obvious difference of flow field and pressure distributions can be also found. The flow fields near both the leading edge and the trailing edge changed greatly. The back flow on the upper side from trailing edge was also greatly decreased. These changes make the power characteristics of the rotor with auxiliary blade improve more greatly than the original rotor.

Figure 10 shows the distribution of velocity and pressure around the blades under the conditions of $\mathrm{B}_{0}$ and $\mathrm{B}_{3}$ at three typical azimuth angles of $0^{\circ}, 90^{\circ}$, and $150^{\circ}$ based on the analysis in Section 4.2. Figure 11 shows the velocity contours of working condition $\mathrm{B}$.

For $\alpha=0^{\circ}$, according to Figure 10(a), the flow field and pressure distribution are different with the working condition A. For the condition of Blade I, the pressure difference between the upper side and lower side of main blade becomes smaller slightly. However, for Blade II, there is a rather negative pressure zone above the upper side of the main blade near the leading edge. There is also a positive pressure zone on the upper side of the main blade by the existence of auxiliary blade. These changes make Blade II with auxiliary blade produce lager torque and power than the original rotor.
For $\alpha=90^{\circ}$ according to Figure 10(b), the negative pressure zone on the lower side of main Blade I becomes wider with the existence of auxiliary blade than the original one. For the Blade II, the negative pressure zone is also increased and there is negative zone on lower side of the auxiliary blade as well. Therefore, at this azimuth angle, the power coefficient of the rotor with auxiliary blade became larger than the original one. For $\alpha=150^{\circ}$ according to Figure $10(\mathrm{c})$, it is obvious that there is a wider negative pressure zone near the lower side of the main Blade I with auxiliary blade than the original main blade. The pressure difference between the upper and lower side will become larger and can supply larger torque and power for the rotor.

4.4. Static Torque Coefficient. Figure 12 shows the static torque coefficient $\left(C_{\mathrm{ts}}\right)$ at different azimuth angle during a rotation period for the working conditions of $A_{0}, A_{5}, B_{0}$, and $B_{3}$. The calculation interval is $10^{\circ}$. The static torque coefficient is defined as (9) as shown below:

$$
C_{\mathrm{ts}}=\frac{T_{\mathrm{s}}}{(1 / 2) \rho A R U^{2}}
$$

where $T_{\mathrm{s}}(\mathrm{N} \cdot \mathrm{m})$ is the static torque. 

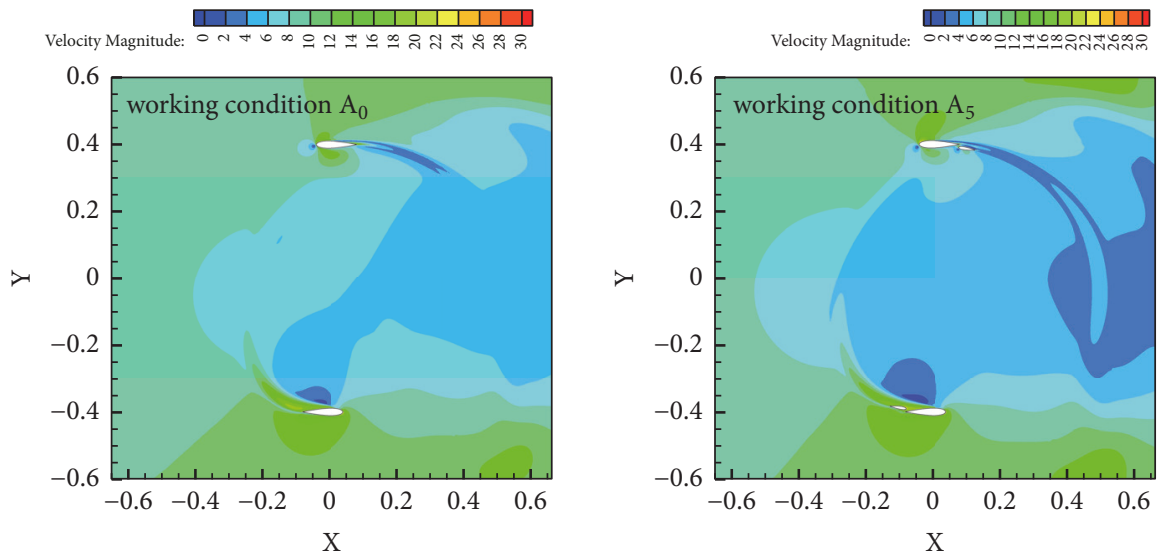

(a) $\alpha=0^{\circ}$
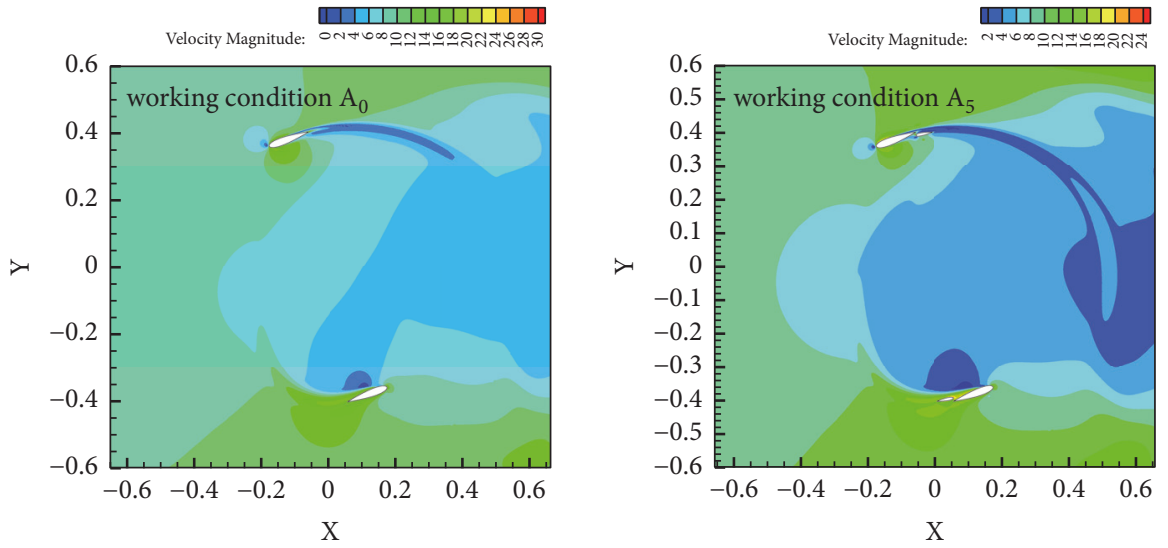

(b) $\alpha=20^{\circ}$
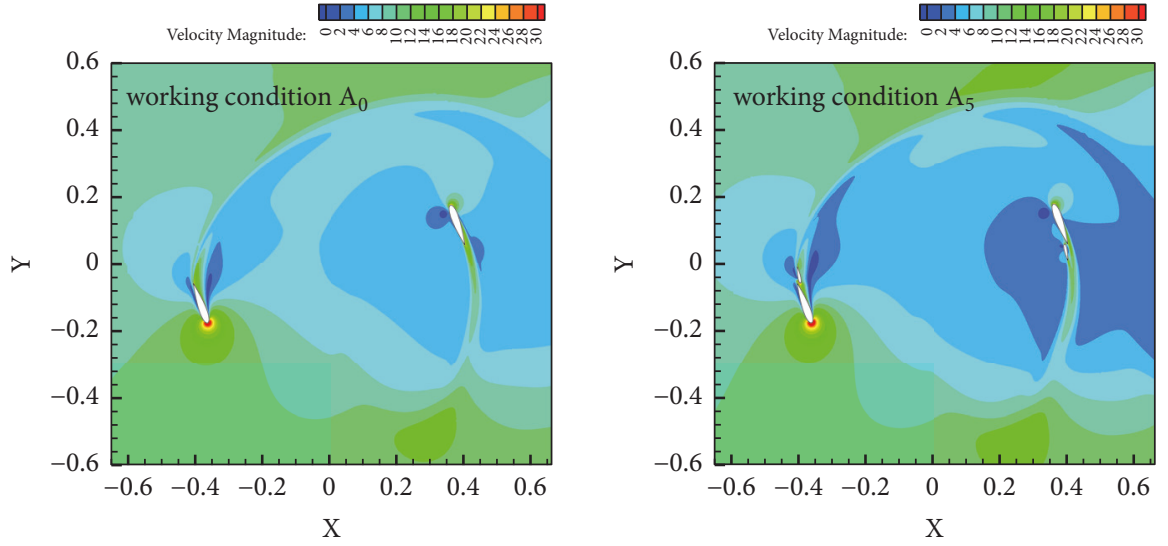

(c) $\alpha=110^{\circ}$

FIGURE 9: Velocity contours of working condition A.

Generally speaking, the whole static torque performance of the rotor with NACA0024 airfoil is better than the rotor with NACA0018 airfoil. It can be thought that the SB-VAWT with thicker relative thickness of NACA symmetric series airfoils has better static torque performance. This situation is also the same for the rotor with auxiliary blade according to Figure 12. For the working condition $\mathrm{A}_{5}$, the static torque coefficients increased by adding auxiliary blade mainly at the azimuth angle from $30^{\circ}$ to $80^{\circ}$ and from $130^{\circ}$ to $180^{\circ}$. For the working condition $\mathrm{B}_{3}$, the static torque coefficients increased by adding auxiliary blade mainly at the azimuth angle from $60^{\circ}$ to $90^{\circ}$ and from $120^{\circ}$ to $180^{\circ}$. The azimuth angle of the maximum static torque coefficient of $\mathrm{A}_{5}$ was increased by nearly $70.5 \%$ more than that of $\mathrm{A}_{0}$ at the azimuth angle of $70^{\circ}$. The average static torque coefficient of SB-VAWT installed with auxiliary blades increased by about $43.5 \%$ more than the rotor without auxiliary blade. For working condition of $\mathrm{B}$, the difference of static torque coefficient between $B_{0}$ and $B_{3}$ was 

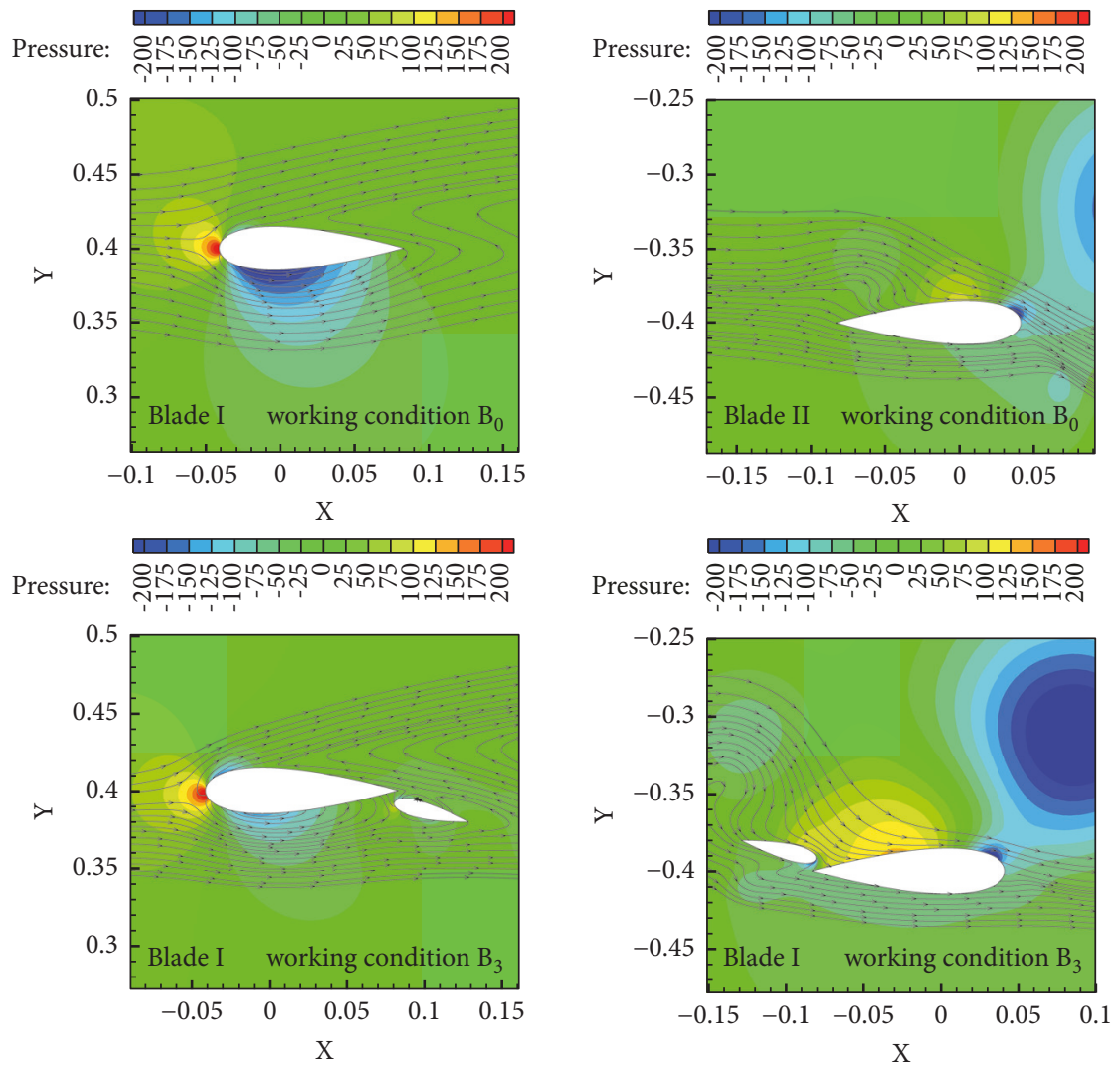

(a) $\alpha=0^{\circ}$
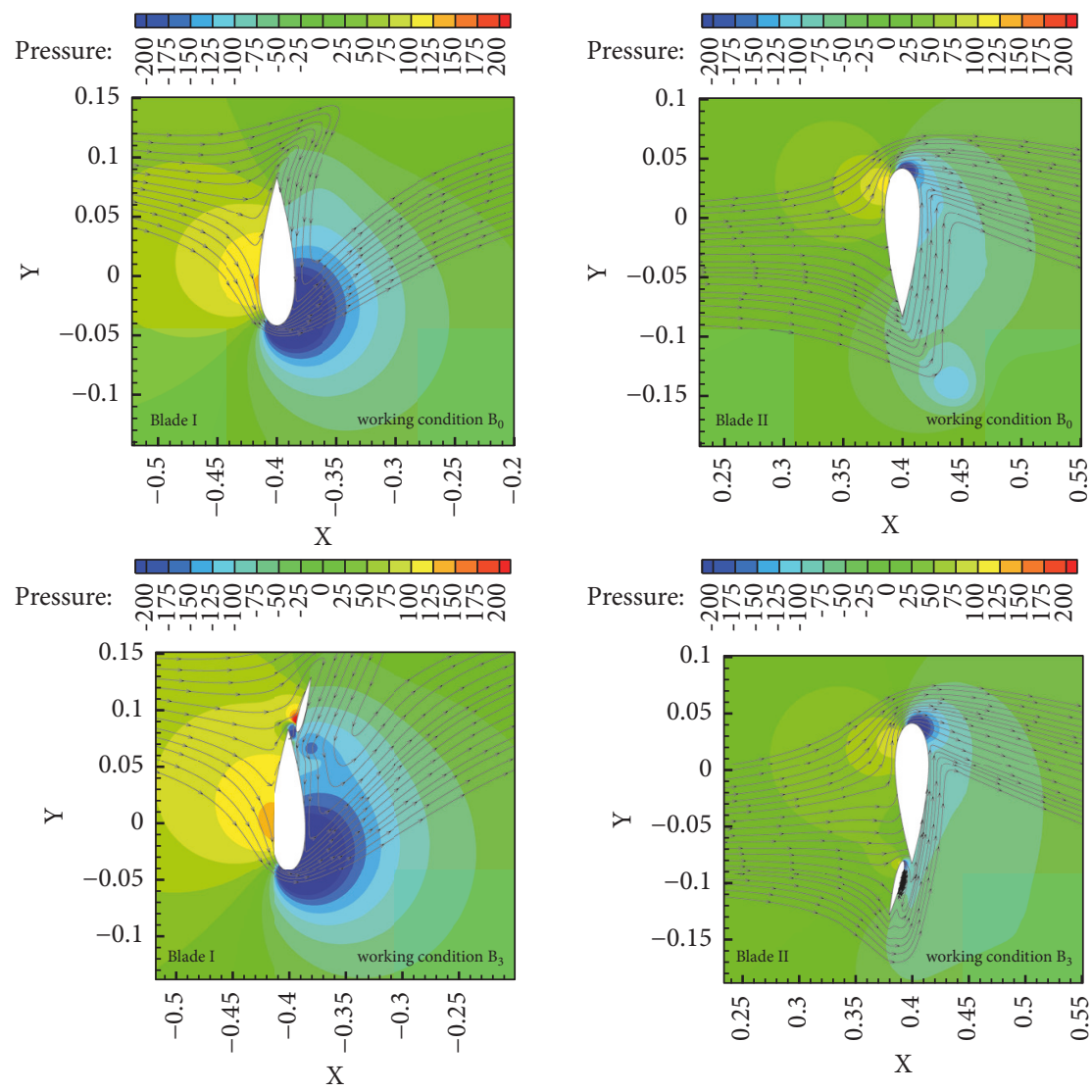

(b) $\alpha=90^{\circ}$

Figure 10: Continued. 

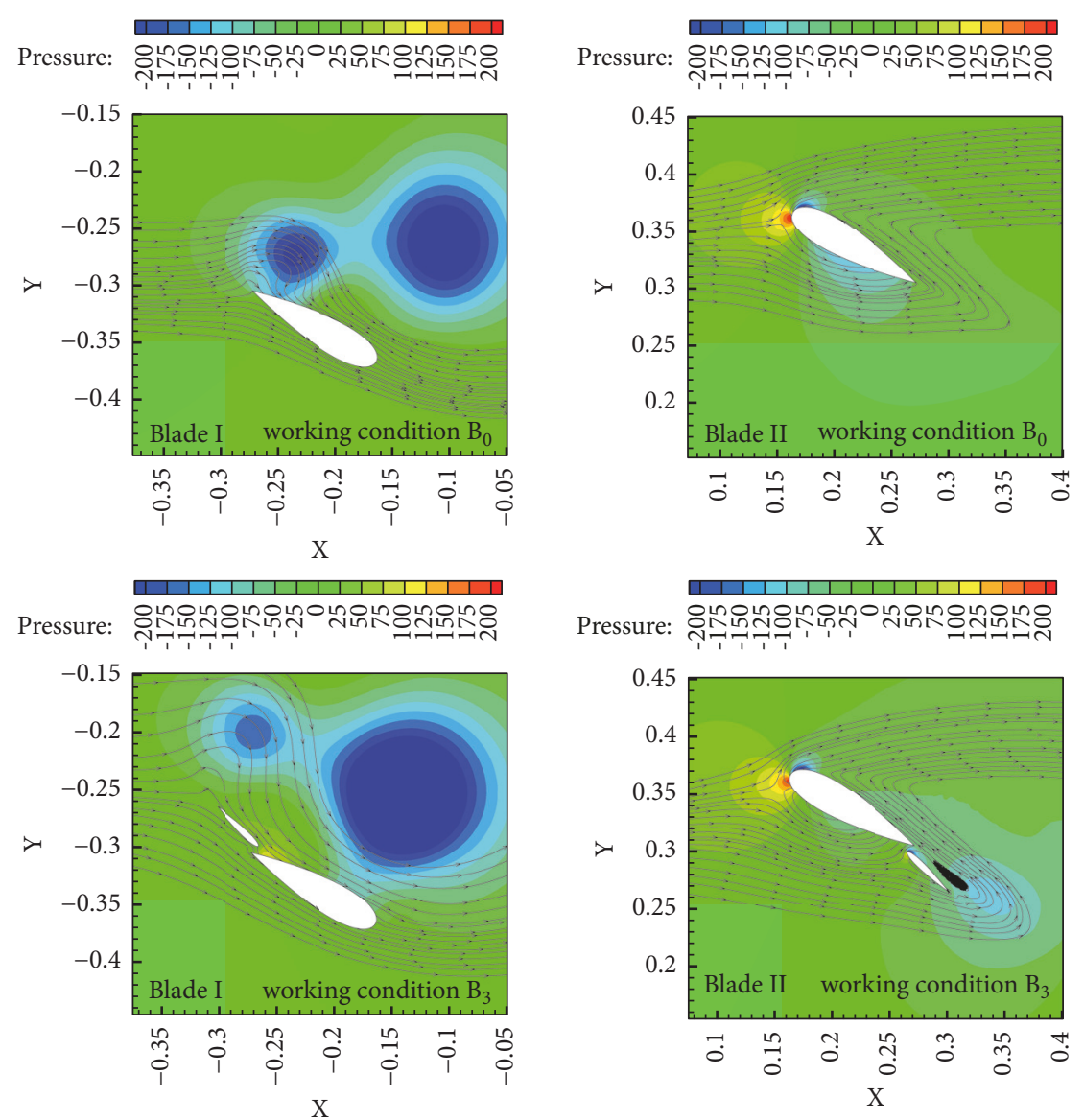

(c) $\alpha=150^{\circ}$

FIGURE 10: Streamline and pressure contours around wind turbine blade of working condition B.

nearly 3.6 times at the azimuth angle of $170^{\circ}$. It can be also found that the negative static torque coefficients disappear by using auxiliary blade. The static torque performance for both types of rotor with different blade relative thickness has been improved.

4.5. Static Flow Field. Figure 13 shows the distribution of velocity and pressure around the blades under the condition of $A_{0}$ and $A_{5}$ at the azimuth angle of $70^{\circ}$ and $160^{\circ}$ based on the analysis in Section 4.4. Figure 14 shows the static velocity contours at two azimuth angles of working condition A.

The improvement effect of auxiliary blade on the static flow field of SB-VAWT was more obvious than that of the dynamic flow field. For $\alpha=70^{\circ}$, according to Figure 13(a), it can be found that there is larger area of negative pressure zone near the lower side of Blade I based on the existence of auxiliary blade. This is also the same condition for the Blade II, which made the static torque coefficient increase greatly at this azimuth angle. For $\alpha=160^{\circ}$, according to Figure 13(b), bigger changes of the pressure distribution between the two main blades with and without auxiliary cannot be found. However, the larger area of vortex can be seen clearly on the upper side of Blade I and lower side of Blade II. Because the rotor is in static condition, the larger vortex will produce larger drag force to the blade, which caused the static torque to increase more than the original rotor without auxiliary at this azimuth angle.

Figure 15 shows the distribution of velocity and pressure around the blades under the conditions of B0 and B3 at the azimuth angles of $80^{\circ}$ and $170^{\circ}$ based on the analysis in Section 4.4. For both the azimuth angles, the auxiliary blade changes the flow field on the upper side of Blade I and Blade II. The static torque coefficient increased at the two azimuth angles, especially for $\alpha=170^{\circ}$. Figure 16 shows the static velocity contours at two azimuth angles of working condition B.

\section{Conclusions}

Under the research condition of this study, the main conclusions are summarized as follows:

(1) The installation of auxiliary blade with suitable parameters can improve both the static torque and power performance of the SB-VAWT with NACA 

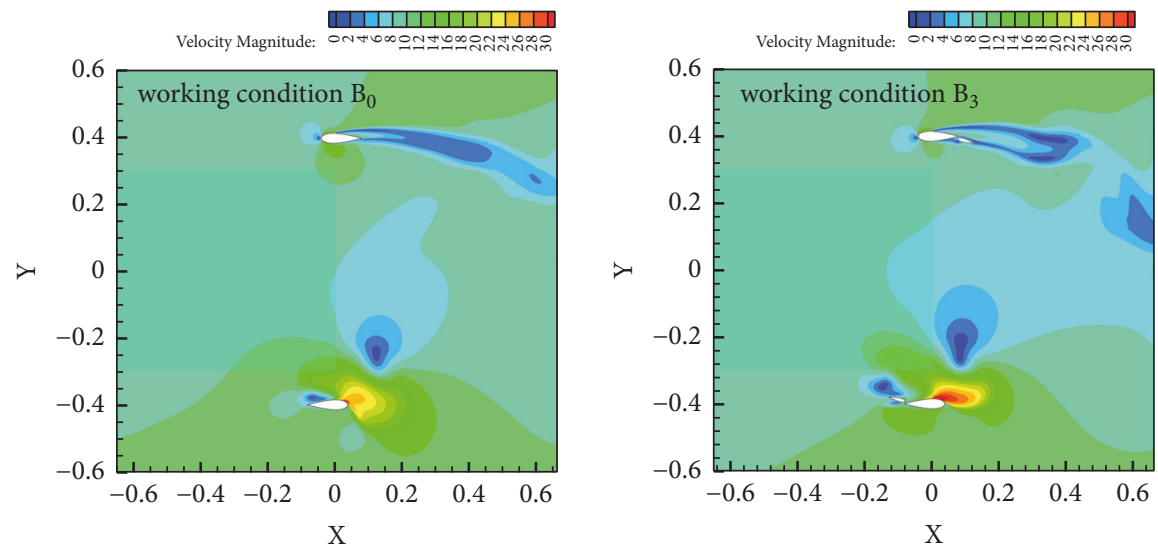

(a) $\alpha=0^{\circ}$
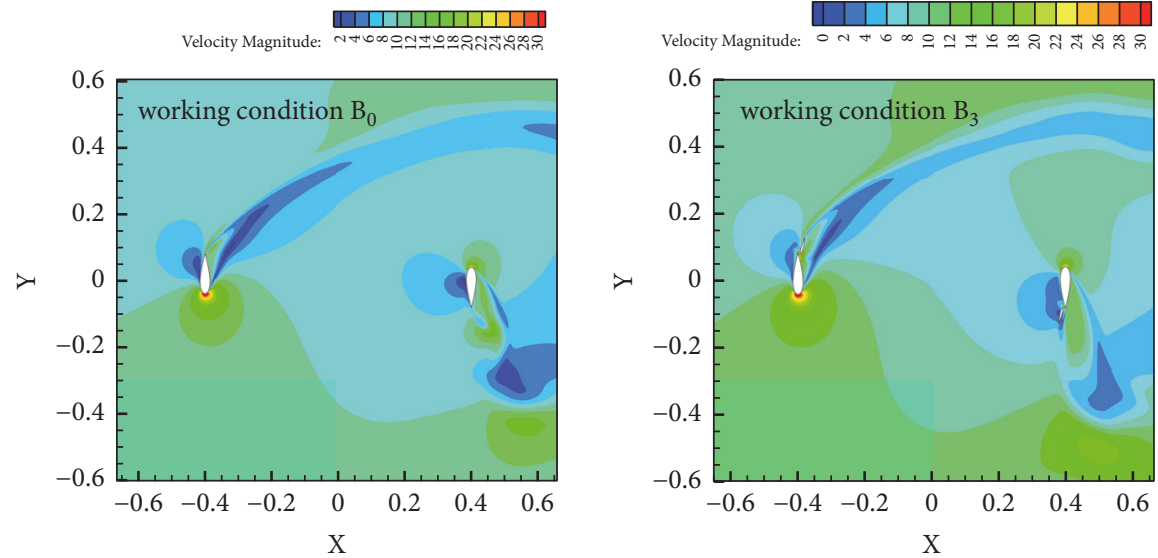

(b) $\alpha=90^{\circ}$
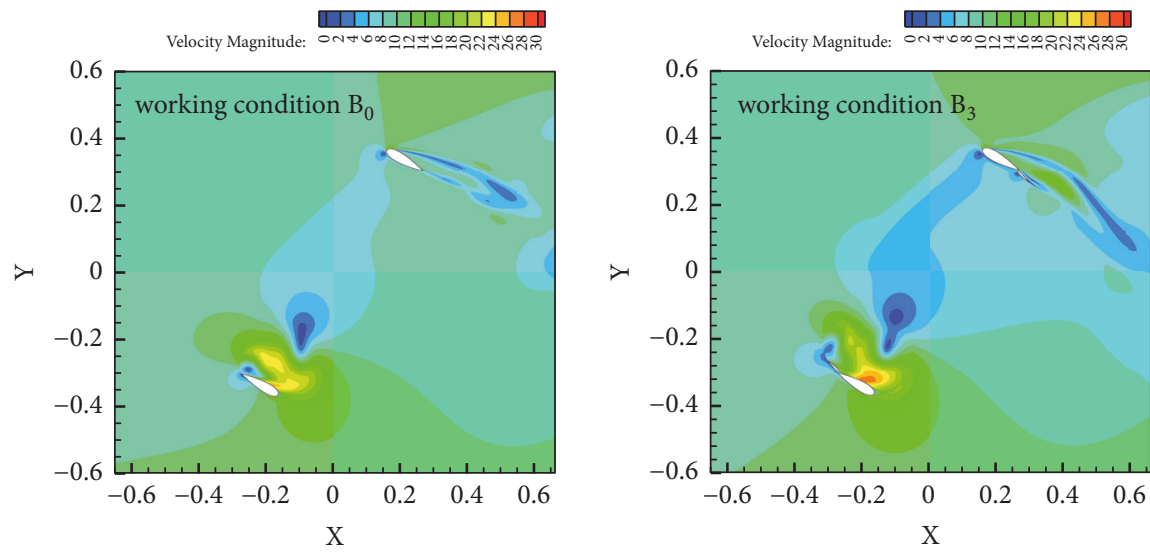

(c) $\alpha=150^{\circ}$

FIGURE 11: Velocity contours of working condition B.

symmetric series airfoils, especially for NACA0018 airfoil.

(2) The relative thickness and fixing angle of auxiliary blade affect the power coefficient greatly. The relative thickness of auxiliary blade may be almost the same with the main blade. A small fixing angle installed against main blade such as $5^{\circ}$ can increase the power coefficient of the rotor.
(3) The power performance improvement by auxiliary blade is mainly because the auxiliary blade changes the pressure difference between the upper and lower side of the main blade at some azimuth angles. For the starting performance improvement, the existence of auxiliary blade increases the drag area at some azimuth angles which makes the static torque characteristics increase. 


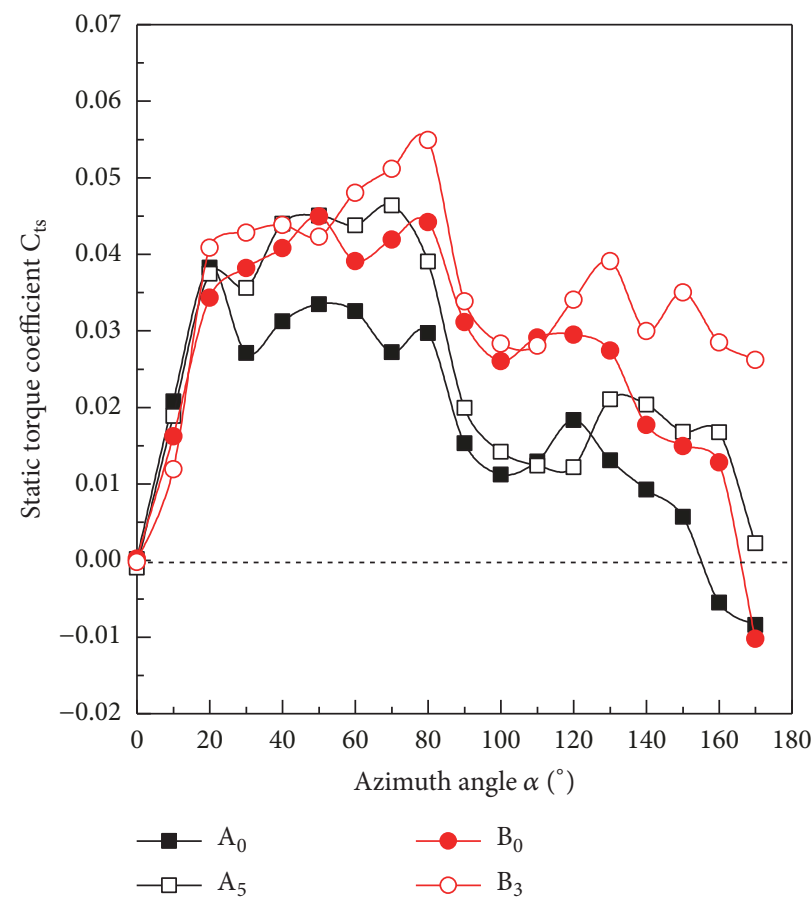

FIgURE 12: Static torque coefficients in one rotation period.
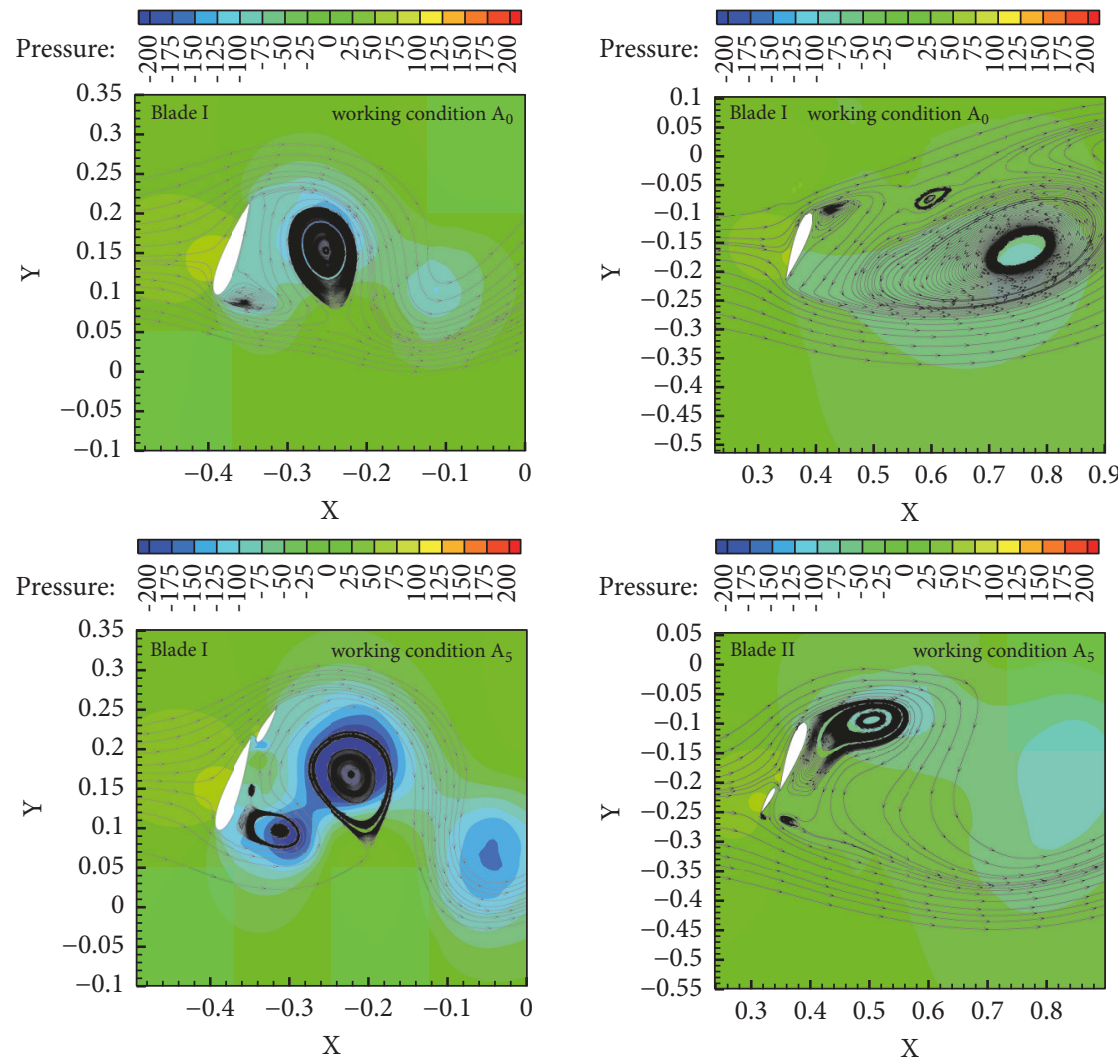

(a) $\alpha=70^{\circ}$

FIGURE 13: Continued. 

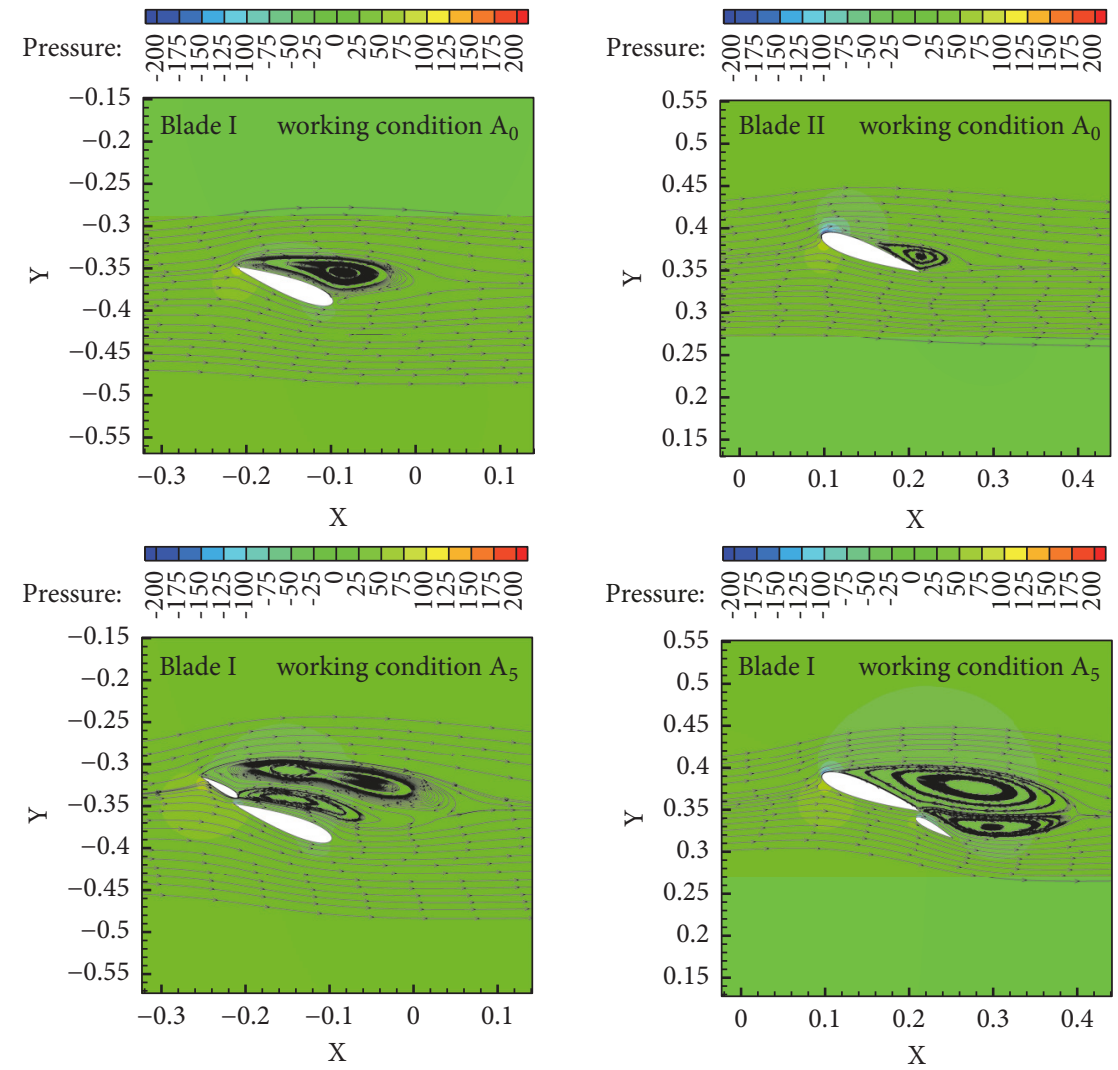

(b) $\alpha=160^{\circ}$

FIgURE 13: Static flow fields at two azimuth angles of working condition A.
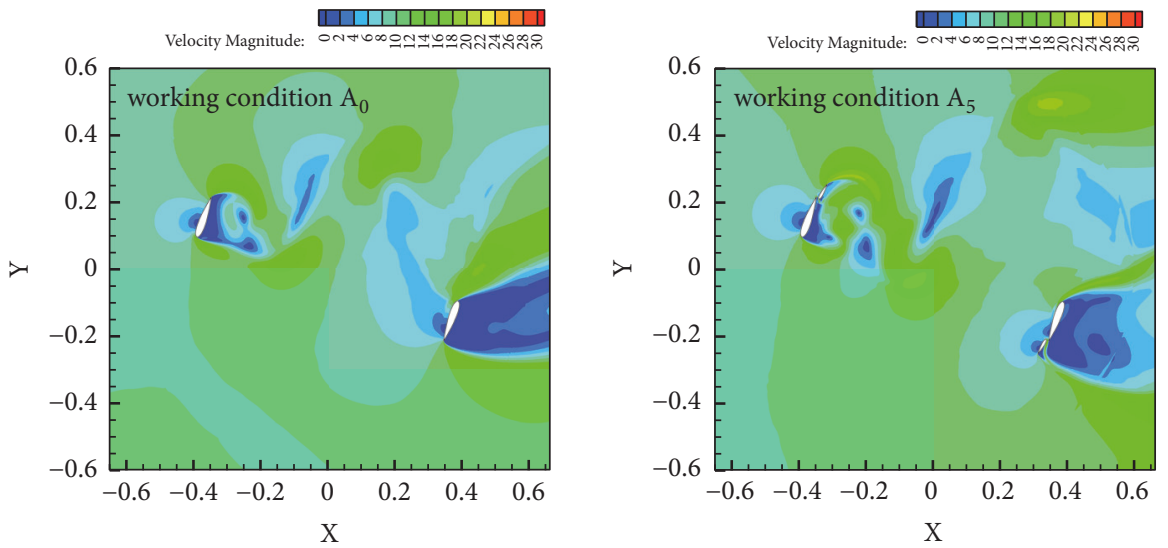

(a) $\alpha=70^{\circ}$
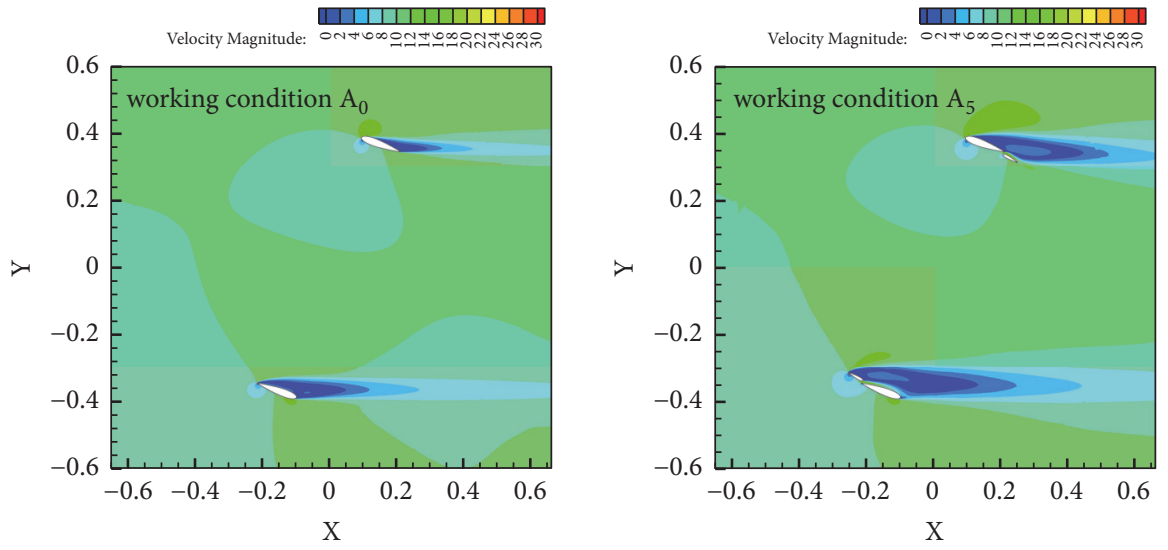

(b) $\alpha=160^{\circ}$

Figure 14: Static velocity contours at two azimuth angles of working condition A. 

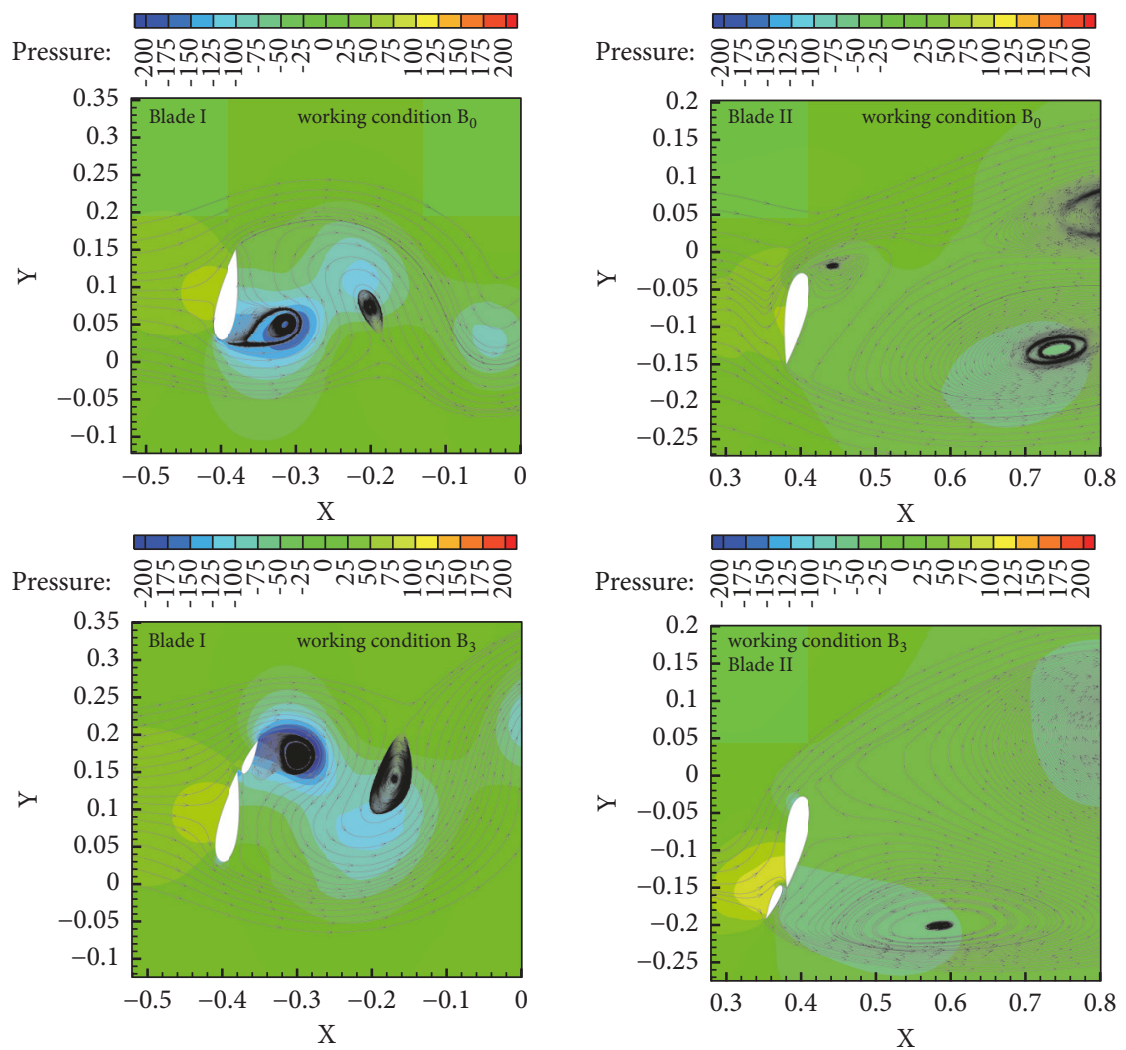

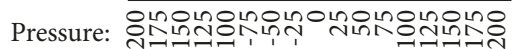

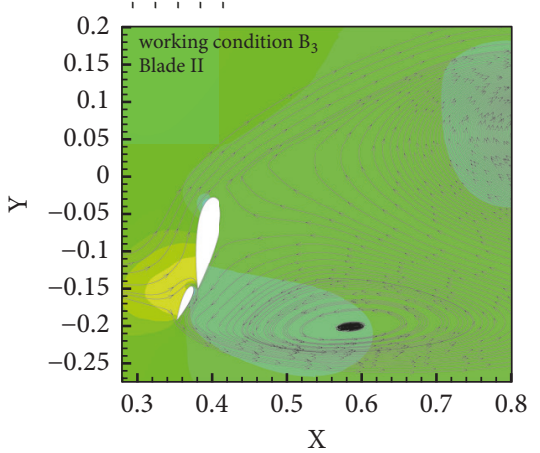

(a) $\alpha=80^{\circ}$
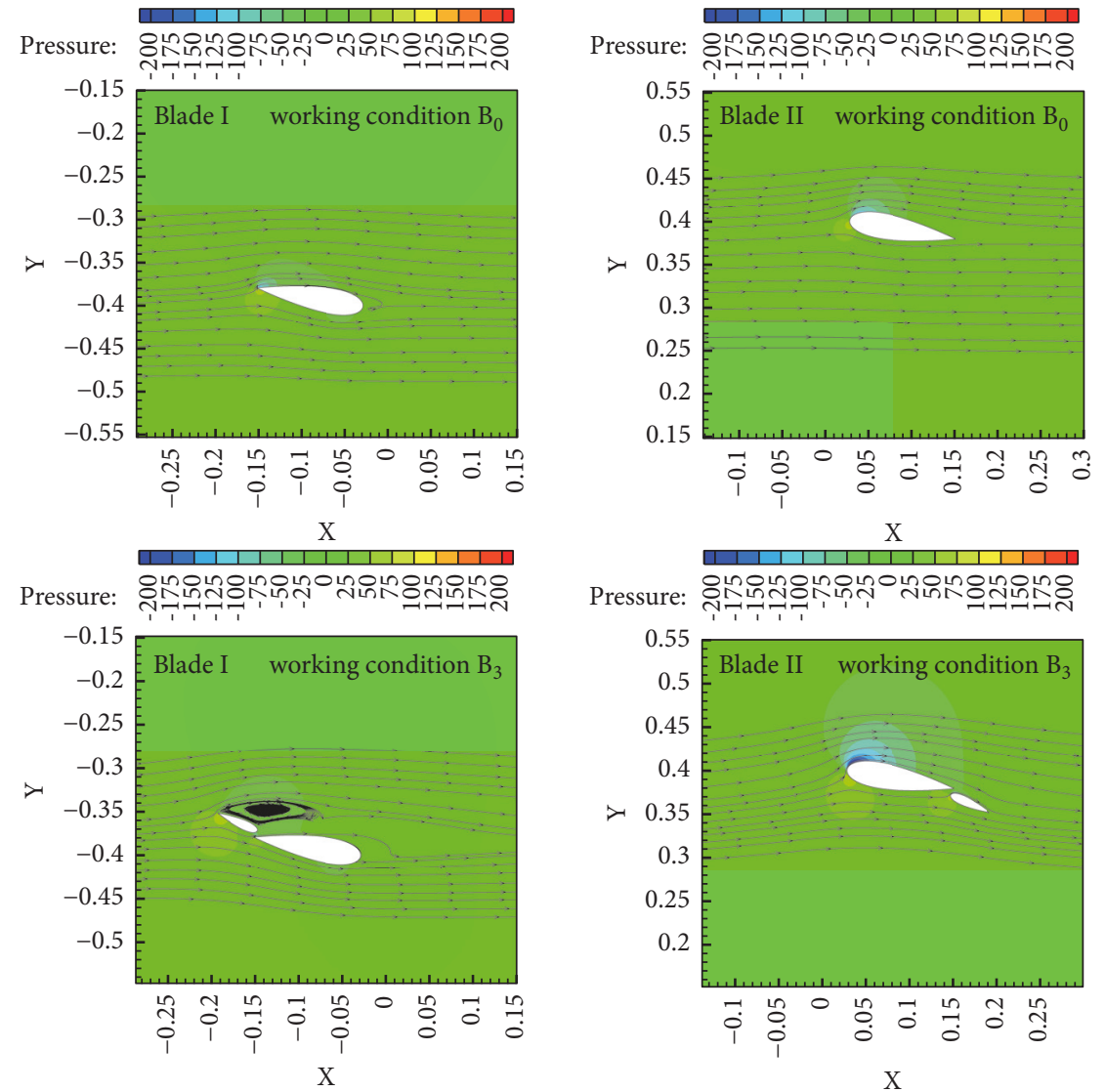

(b) $\alpha=170^{\circ}$

FIGURE 15: Static flow fields at two azimuth angles of working condition B. 

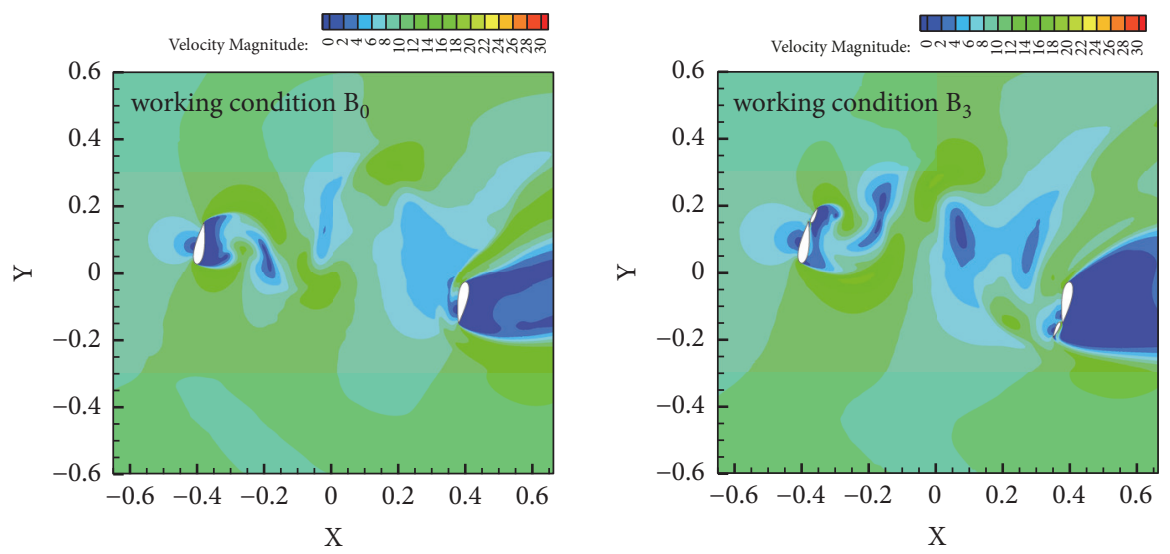

(a) $\alpha=80^{\circ}$
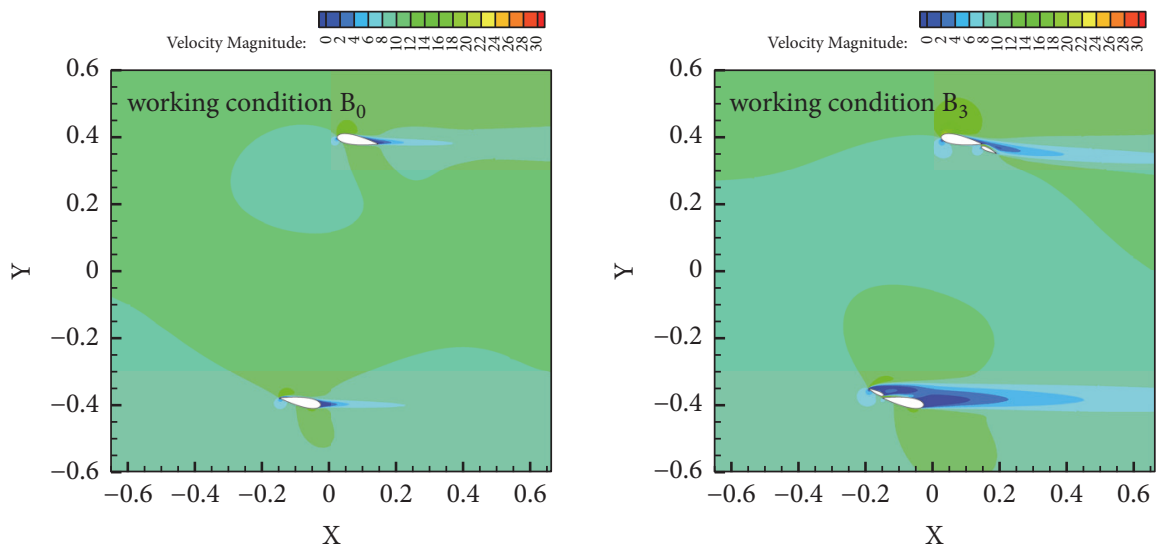

(b) $\alpha=170^{\circ}$

FIgURE 16: Static velocity contours at two azimuth angles of working condition B.

\section{Data Availability}

The data used to support the findings of this study are included within the article.

\section{Conflicts of Interest}

The authors declare that there are no conflicts of interest regarding the publication of this paper.

\section{Acknowledgments}

This research is sponsored by the Foundation of Major Science and Technology Project of Tibet Autonomous Region of China (No. XZ201801-GA-03) and the Key Laboratory of Wind Energy and Solar Energy Technology, Ministry of Education (No. 2017MS02). The authors thank them for their support.

\section{References}

[1] K. Tagawa and Y. Li, "A wind tunnel experiment of self-starting capability for straight-bladed vertical axis wind turbine," Journal of Drainage and Irrigation Machinery Engineering, vol. 36, no. 2, pp. 136-140, 2018.
[2] B. Zhao, H. Ma, Y. Zhao et al., "Analysis on application of vertical axis wind turbines in Qinghai-Tibet Plateau," Journal of Drainage and Irrigation Machinery Engineering, vol. 36, no. 3, pp. 250-256, 2018 (Chinese).

[3] W. Ji, J. Wang, S. Xue et al., "Analysis of vertical axis wind turbine power changing with rotating speed from vertical and horizontal flow fields," Journal of Drainage and Irrigation Machinery Engineering, vol. 36, no. 2, pp. 166-171, 2018 (Chinese).

[4] Y. Li, Y. Zheng, S. Zhao et al., "A review on aerodynamic characteristics of straight-bladed vertical axis wind turbine," Acta Aerodynamica Sinica, vol. 35, no. 6, pp. 368-382, 2017.

[5] L. Yan, Z. Shouyang, Y. Jiang et al., "Numerical simulation of effects of blade number on torque coefficient of vertical axis wind turbine with plate added at blade trailing edge," Journal of Drainage and Irrigation Machinery Engineering, vol. 36, no. 3, pp. 215-222, 2018 (Chinese).

[6] M. Borg, M. Collu, and A. Kolios, "Offshore floating vertical axis wind turbines, dynamics modelling state of the art. Part II: Mooring line and structural dynamics," Renewable \& Sustainable Energy Reviews, vol. 39, pp. 1226-1234, 2014.

[7] M. Borg and M. Collu, "Frequency-domain characteristics of aerodynamic loads of offshore floating vertical axis wind turbines," Applied Energy, vol. 155, pp. 629-636, 2015.

[8] M. A. Singh and A. Biswas, "Investigation of self-starting and high rotor solidity on the performance of a three S1210 blade 
H-type Darrieusrotor," Journal of Renewable Energy, vol. 76, pp. 381-387, 2015.

[9] Y. Li, S. Zhao, K. Tagawa, and F. Feng, "Starting performance effect of a truncated-cone-shaped wind gathering device on small-scale straight-bladed vertical axis wind turbine," Energy Conversion and Management, vol. 167, pp. 70-80, 2018.

[10] Z.-T. Yang, J.-W. Wang, X.-Q. Dong et al., "Research on the influence of wind turbine vane tip vortex trajectory," Journal of Engineering Thermophysics, vol. 35, no. 12, pp. 2398-2401, 2014 (Chinese).

[11] Y. Li, T. Zhang, K. Tagawa et al., "Numerical simulation on torque characteristics of vertical axis wind turbine with curved plate adding at blade trailing edge," Journal of Northeast Agricultural University, vol. 48, no. 3, pp. 72-79, 2017.

[12] W. Husien, W. El-Osta, and E. Dekam, "Effect of the wake behind wind rotor on optimum energy output of wind farms," Journal of Renewable Energy, vol. 49, pp. 128-132, 2013.

[13] F. González-Longatt, P. P. Wall, and V. Terzija, "Wake effect in wind farm performance: Steady-state and dynamic behavior," Journal of Renewable Energy, vol. 39, no. 1, pp. 329-338, 2012.

[14] B. Sanderse, S. P. Van Der Pijl, and B. Koren, "Review of computational fluid dynamics for wind turbine wake aerodynamics," Wind Energy, vol. 14, no. 7, pp. 799-819, 2011.

[15] K. Sagara, M. Ideno, K. Kagaya et al., "A103 experiment of dimensional airfoil of straight wing vertical axis wind turbine," National Symposium on Power and Energy Systems, vol. 2012, pp. 7-8, 2012.

[16] F. Feng, Y. Li, S. Zhao et al., "Numerical simulation of aerodynamic characteristics of VAWT with lift-drag starter," ActaEnergiae Solaris Sinica, vol. 39, no. 4, pp. 1052-1059, 2018 (Chinese).

[17] F. Feng, S. Zhao, C. Qu et al., "Research on aerodynamic characteristics of straight-bladed vertical axis wind turbine with S series airfoils," International Journal of Rotating Machinery, vol. 2018, Article ID 8350243, 13 pages, 2018.

[18] M. Zhou, R.-G. Wang, Z.-H. Cao, and X.-Y. Zhang, "Influence of slot treatment on flow performance of blade trailing edge," Journal of Aerospace Power, vol. 22, no. 7, pp. 1100-1105, 2007 (Chinese).

[19] Z. Liru, W. Jianwen, Y. Haipeng et al., "Research on characteristics of the flow field of wind turbine with the S-type tip vane," Journal of Engineering Thermophysics, vol. 33, no. 5, pp. 788-791, 2012 (Chinese).

[20] X. Shen, J. Chen, P. Liu, X. Zhu, and Z. Du, "Effect of winglets on aerodynamic performance of wind turbine," Acta Energiae Solaris Sinica, vol. 35, no. 2, pp. 183-189, 2014 (Chinese).

[21] L. Yan, Z. Yufang, T. Jing et al., "Numerical simulation on aerodynamic characteristics of vertical axis wind turbine with auxiliary blade behind main blade," Journal of Northeast Agricultural University, vol. 47, no. 7, pp. 76-81, 2016 (Chinese).

[22] S. Liao, C. Li, J. Nie et al., "The analysis of aerodynamic performance for small H type VAWT based on different airfoils," Machine Design and Research, vol. 27, no. 3, pp. 108-111, 116, 2011 (Chinese).

[23] Y. Qiuping and X. Deke, "Effect of fixed angles on aerodynamic performance of H-VAWT," Acta Energiae Solaris Sinica, vol. 38, no. 9, pp. 2544-2551, 2017 (Chinese).

[24] M. H. Mohamed, "Performance investigation of H-rotor Darrieus turbine with new airfoil shapes," Energy, vol. 47, no. 1, pp. 522-530, 2012.
[25] W. Zuo, S. Kang, Y.-X. Qiu et al., "Numerical simulation of the aerodynamic performance of $\mathrm{H}$ type wind turbine," Journal of Engineering Thermophysics, vol. 34, no. 8, pp. 1462-1465, 2013.

[26] S. Craig, I. Sheikh, W. Alasdair et al., "Efficiency improvement of vertical axis wind turbines with an up stream deflector," Energy Procedia, vol. 118, pp. 141-148, 2017.

[27] T. L. Young and C. L. Hee, "Numerical study of the aerodynamic performance of a $500 \mathrm{~W}$ darrieus-type vertical axis wind turbine," Renewable Energy, vol. 83, pp. 407-415, 2015.

[28] R. Howell, N. Qin, J. Edwards, and N. Durrani, "Wind tunnel and numerical study of a small vertical axis wind turbine," Journal of Renewable Energy, vol. 35, no. 2, pp. 412-422, 2010. 


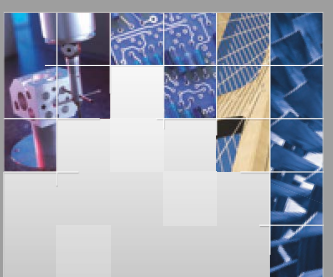

\section{Enfincering}
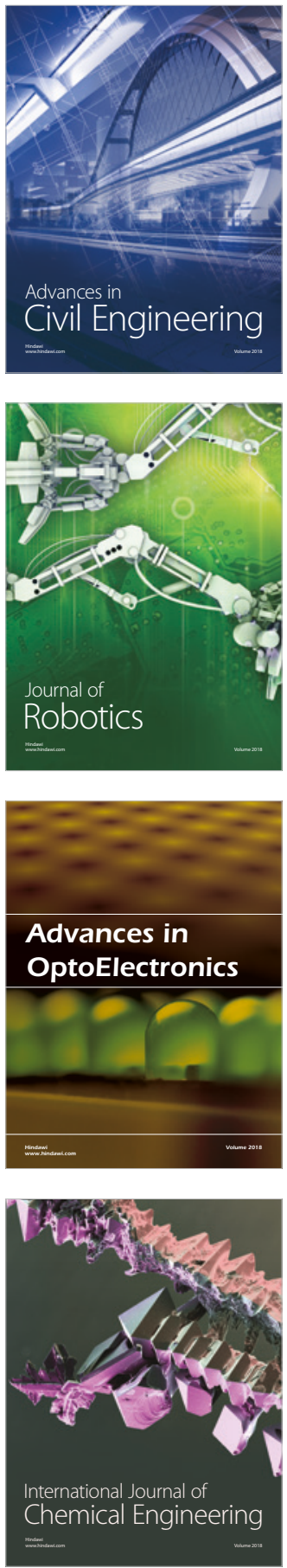

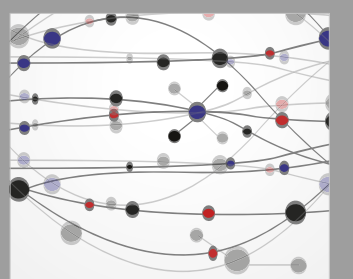

\section{Rotating \\ Machinery}

The Scientific World Journal

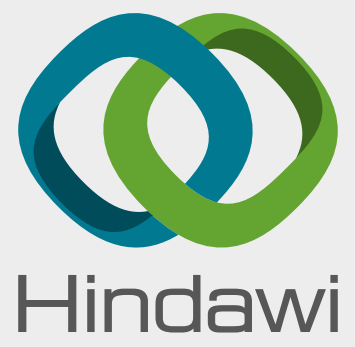

Submit your manuscripts at

www.hindawi.com
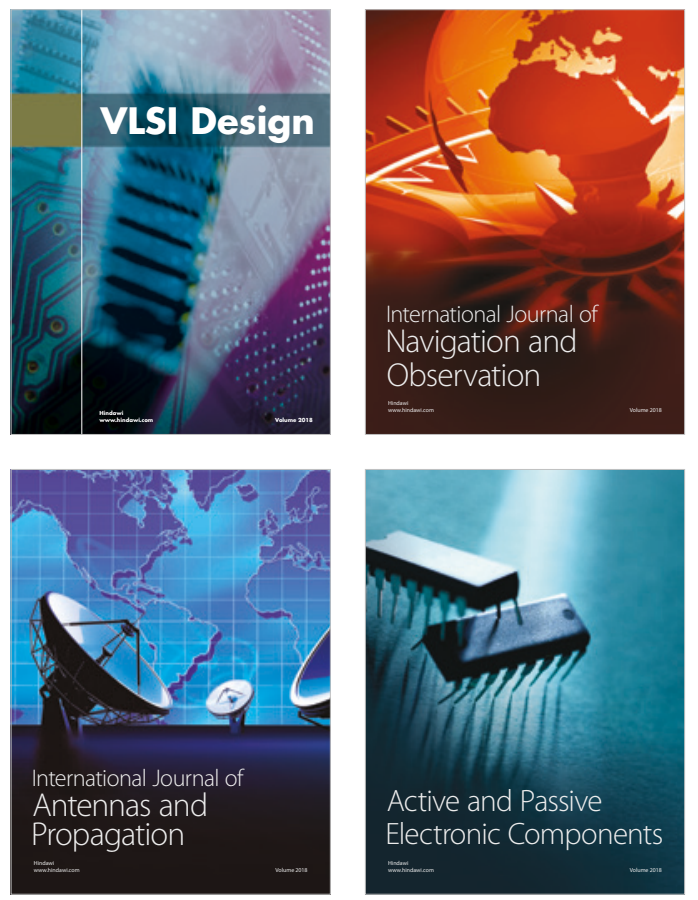
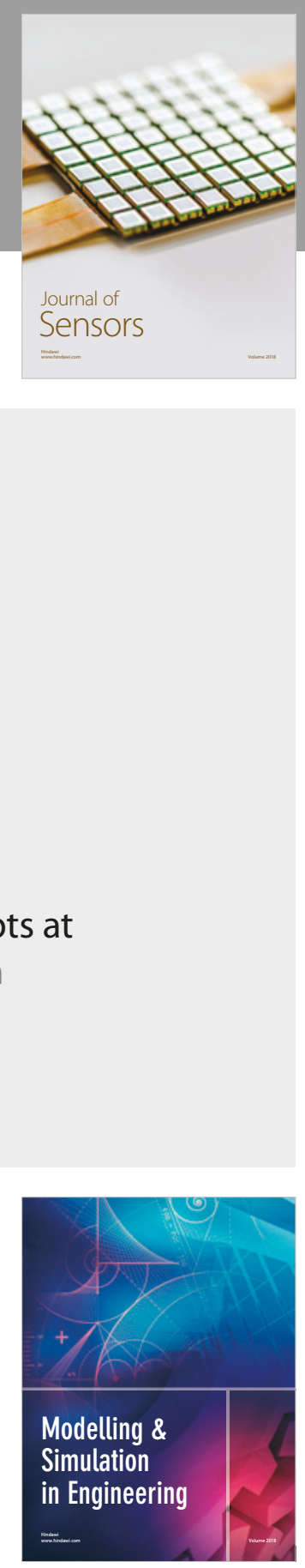

\section{Advances \\ Multimedia}
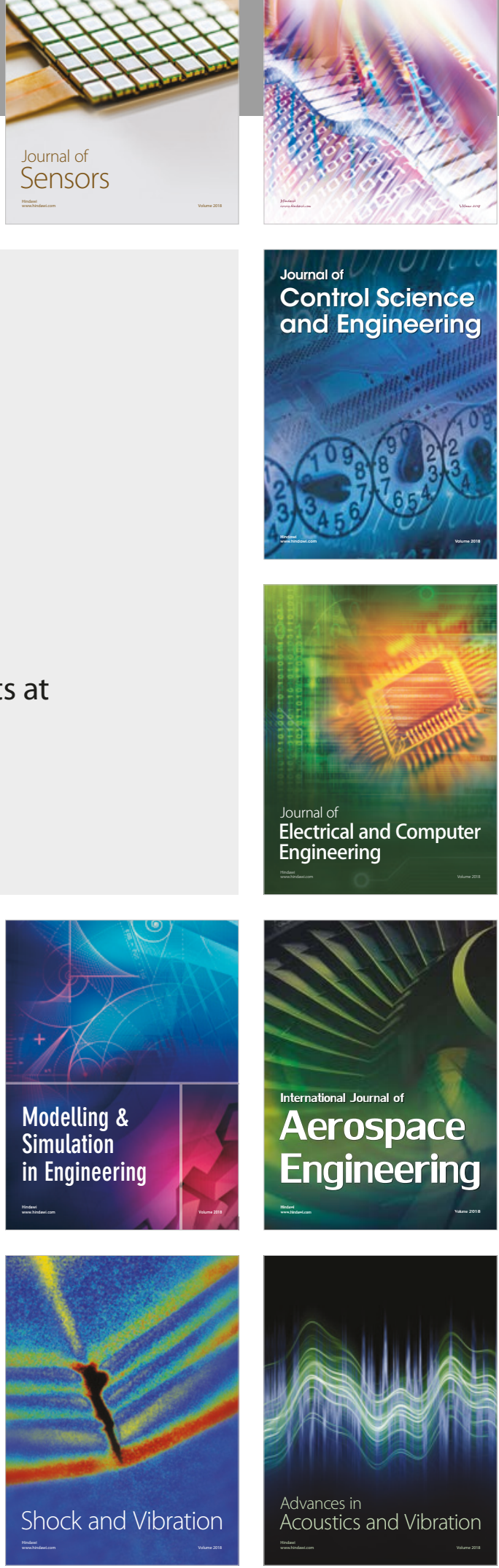